\title{
Apple Peel and Flesh Contain Pro-neurogenic Compounds
}

\author{
Muhammad Ichwan, , 2,3,10 Tara L. Walker, ${ }^{1,2,4,10}$ Zeina Nicola, ${ }^{1,2}$ Jutta Ludwig-Müller, ${ }^{5}$ Christoph Böttcher, ${ }^{6}$ \\ Rupert W. Overall, ${ }^{1,2}$ Vijay S. Adusumilli, ${ }^{1,2}$ Merve Bulut, ${ }^{1,2}$ Alex M. Sykes, ${ }^{7}$ Norbert Hübner, ${ }^{8}$ \\ Gerardo Ramirez-Rodriguez, ${ }^{9}$ Leonardo Ortiz-López, ${ }^{9}$ Enrique A. Lugo-Hernández, ${ }^{9}$ \\ and Gerd Kempermann ${ }^{1,2, *}$ \\ ${ }^{1}$ Center for Regenerative Therapies Dresden (CRTD), Technische Universität Dresden, 01307 Dresden, Germany \\ ${ }^{2}$ German Center for Neurodegenerative Diseases (DZNE) Dresden, 01307 Dresden, Germany \\ ${ }^{3}$ Department of Pharmacology and Therapeutics, Faculty of Medicine, Universitas Sumatera Utara, Medan, 20155, Indonesia \\ ${ }^{4}$ Queensland Brain Institute (QBI), The University of Queensland, Brisbane 4072, Australia \\ ${ }^{5}$ Institute for Botany, Technische Universität Dresden, 01062 Dresden, Germany \\ ${ }^{6}$ Leibniz Institute of Plant Biochemistry, 06120 Halle (Saale), Germany \\ ${ }^{7}$ Griffith Institute for Drug Discovery, Griffith University, Brisbane 4111, Australia \\ ${ }^{8}$ Max-Delbrück-Centrum für Molekulare Medizin (MDC), 13125 Berlin, Germany \\ ${ }^{9}$ Laboratory of Neurogenesis, Division of Clinical Investigations, National Institute of Psychiatry "Ramon de laFuente Muñiz," Mexico DF, Mexico \\ ${ }^{10}$ These authors contributed equally \\ *Correspondence: gerd.kempermann@dzne.de \\ https://doi.org/10.1016/j.stemcr.2021.01.005
}

\section{SUMMARY}

As mammals evolved with exposure to particular diets, naturally abundant compounds may have become part of the set of environmental co-determinants that shaped brain structure and function. Here we investigated whether bioactive factors found in apples directly affect hippocampal neurogenesis in the adult mouse. We found that quercetin, the most abundant flavanol in apple peel, was anti-proliferative at high concentrations but pro-neurogenic at low concentrations. This was confirmed in vivo, with intraperitoneally delivered quercetin promoting survival and neuronal differentiation, without affecting proliferation. Using a bioassay-guided fractionation approach we also identified additional pro-neurogenic compounds in apple flesh that were not related to flavonoids. We found that 3,5-dihydroxybenzoic acid significantly increased neural precursor cell proliferation and neurogenesis. This work shows that both flavonoids and 3,5-dihydroxybenzoic acid are pro-neurogenic, not only by activating precursor cell proliferation but also by promoting cellcycle exit, cellular survival, and neuronal differentiation.

\section{INTRODUCTION}

"An apple a day keeps the doctor away." There may be some truth to this aphorism. Apart from being a source of energy, food is known to influence an individual's overall fitness. A growing number of studies have demonstrated the health benefits of phytochemicals, the chemical substances found in plants (for review see Dillard and German, 2000). Active dietary compounds are also vital for maintaining cognitive function. One of the processes underlying this maintenance is brain plasticity, whereby structural and functional modifications occur in response to internal and external stimuli. Adult hippocampal neurogenesis is a particular form of brain plasticity in which functional neurons are generated throughout life and integrated into the existing circuitry, thereby mediating particular forms of learning and memory.

Flavonoids, the abundant phytonutrients found in fruits and vegetables, can modulate molecular signaling pathways that influence these cognitive processes (Spencer, 2009). Prominent examples of flavonoids and polyphenols are resveratrol (found in the skin of red grapes and in red wine) and epigallocatechin-3-gallate (EGCG; found in green tea). In the case of resveratrol, the biological activity has been traced to the intracellular regulation of Sirt1 and other sirtuins (Prozorovski et al., 2008). We and others have shown that both EGCG and resveratrol affect adult hippocampal neurogenesis (Ortiz-Lopez et al., 2016; Torres-Perez et al., 2015; Yoo et al., 2010). However, although some positive indications have been reported, intervention trials based on the consumption of resveratrol and similar factors have often proved disappointing (van der Made et al., 2015). One reason, other than questions of bioavailability, might be that plants actually contain a very large number of potentially active compounds. Georgiev et al. (2014), for example, list 20 flavonoids from grapes alone, which likely work in concert to produce beneficial effects on central nervous system function, including positive effects on learning and memory.

As apples are one of the most widely consumed fruits worldwide, resulting in a generalized exposure across cultures, we investigated whether they contain substances that sustain or promote adult hippocampal neurogenesis. We took a two-pronged approach, first studying quercetin, the most abundant flavonoid in apple peel (Bhagwat and Haytowitz, 2016), and second extending our investigation to identify additional proneurogenic factors in the fruit. 


\section{RESULTS}

Quercetin Promotes Cell-Cycle Exit and Neuronal Differentiation In Vitro

Quercetin has been linked to several neuroprotective mechanisms, particularly in relation to microglial function (Nichols et al., 2015). This class of phytochemicals can also exert antioxidant effects due to its capacity to scavenge reactive oxygen species. Although quercetin and other natural compounds could affect adult neurogenesis through more than one pathway, we focused on their effect on stem cells, from which the adult-born neurons in the hippocampus originate. We first used the monolayer culture system, which consists of a relatively pure population of putative stem and progenitor cells, to establish a doseresponse curve. In line with reports of inhibitory effects of high doses of quercetin on cancer stem cells, we found that incorporation of the thymidine analog 5-bromo-2'-deoxyuridine (BrdU), as a measure of proliferative activity, was reduced at concentrations of $25 \mu \mathrm{M}$ and higher (Figures $1 \mathrm{~A}$ and $1 \mathrm{~B})$. At concentrations up to $35 \mu \mathrm{M}$, this was not due to increased cytotoxicity, which was, however, detected at even higher doses with the lactate dehydrogenase assay (Figure 1C) and 7-AAD staining (Figure 1D). Cell-cycle analysis based on propidium iodide incorporation and flow cytometric analysis revealed that $25 \mu \mathrm{M}$ quercetin reduced S-phase entry (Figure $1 \mathrm{E}$ ) and caused the cells to accumulate in the G1 phase (Figure 1E). Western blot analysis for cell-cycle-related proteins showed that CDK4 levels were significantly decreased when $25 \mu \mathrm{M}$ quercetin was added to cells grown under proliferation conditions (Figure 1F). In contrast, no change in the expression of either cyclin D1 or p27 was observed following the addition of $25 \mu \mathrm{M}$ quercetin to the proliferating cells (Figure 1F).

The above data indicate that quercetin upregulates the cell-cycle "brake" signal to counteract the mitogenic effects of growth factors. This was further supported by our observation that, in the presence of growth factors, $25 \mu \mathrm{M}$ quercetin increased the number of cells with neuron-like morphology (Figures $1 \mathrm{G}$ and $1 \mathrm{H}$ ) and $\beta$ III-tubulin expression (an immature neuronal marker; Figures $1 \mathrm{H}$ and $1 \mathrm{I}$ ), whereas expression of the stem cell marker nestin was decreased (Figures $1 \mathrm{H}$ and 1J). Taken together, these findings indicate that quercetin can act pro-neurogenically even in the presence of growth factors, which normally maintain neural precursor cells (NPCs) in an undifferentiated and proliferative state in vitro.

Quercetin Promotes In Vitro Cell Survival and Stimulates Adult Neurogenesis In Vivo

The NPCs in monolayer cultures can be induced to differentiate into neurons or astrocytes by removal of growth factors. However, growth factor withdrawal also leads to significant cell death. As polyphenols have been shown to exert neuroprotective effects, we next examined whether quercetin supports cell survival in vitro during differentiation. We found that the addition of $25 \mu \mathrm{M}$ quercetin for 4 days following growth factor withdrawal almost doubled the percentage of surviving cells (Figures 2A-2C).

Given the positive effects of quercetin in vitro, we next examined its effects in vivo. Quercetin was administered orally at $50 \mathrm{mg} / \mathrm{kg}$, a dose previously shown to lead to sufficient accumulation of metabolites in the brain (Ishisaka et al., 2011). Proliferating cells were labeled with iododeoxyuridine (IdU) after 14 days of quercetin treatment, whereas the effect of the treatment on cell survival was assessed in a cohort of cells labeled with chlorodeoxyuridine (CldU) immediately before the treatment began (Figure 2D). After 2 weeks of quercetin treatment we observed a trend toward a decrease in proliferation (Figure 2E). In contrast, the number of $\mathrm{CldU}^{+}$cells was significantly increased (Figure 2F). Quercetin treatment resulted in a net increase in the number of newly born neurons, with a significantly higher percentage of $\mathrm{NeuN}^{+} / \mathrm{CldU}^{+}$cells compared with the control group (Figures $2 \mathrm{G}$ and $2 \mathrm{H}$ ), whereas the number of new astrocytes was unchanged.

Quercetin Induces Endogenous Antioxidants and the AKT Pathway

To determine how quercetin exerts an effect on cell survival, we next performed RNA microarray analysis on cells collected $24 \mathrm{~h}$ after growth factor withdrawal. The expression levels of 3,900 transcripts significantly changed following $25 \mu \mathrm{M}$ quercetin treatment (Figure 3A). The top 10 positively regulated genes (Table S1) were enriched for genes related to oxidative stress (Gsta3, Srxn1, Osgin1), as well as Relaxin1, which has been reported to promote osteoblast differentiation (Moon et al., 2014). Remarkably, we found that Miat, a long non-coding RNA recently identified as a switch gene in lineage-determined neuronal progenitor cells during cortical development (Aprea et al., 2013), was among the top 10 negatively regulated transcripts. To identify putative target pathways we subjected the transcript lists to enrichment with WebGestalt and pathway analysis from the KEGG and WikiPathway databases. Following hypergeometric testing, the top 10 most significantly enriched pathways were identified (Figures $3 \mathrm{~B}$ and 3C). These pathways were then ranked according to the ratio of genes in the sample to the overall number of members in that pathway. In both databases, pathways involved in "cell cycle," "endogenous antioxidative activity," and "cell survival" were significantly enriched, as was mitogen-activated protein kinase (MAPK) signaling. It is known that, depending on their specific chemical structure, flavonoids can either inhibit or activate these 
A

day 0

day 2

day 3

\section{$\mathrm{GF}(20 \mathrm{ng} / \mathrm{ml}$ bFGF + EGF)}

B

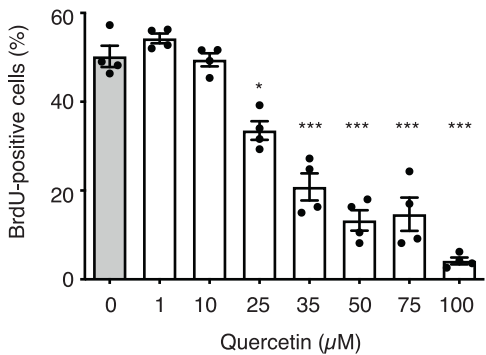

D
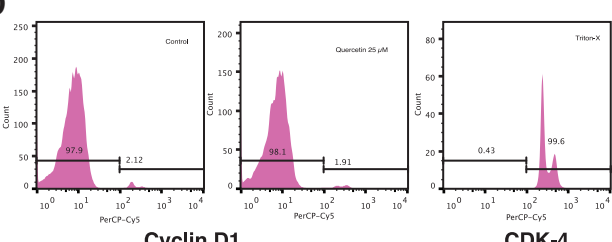

E
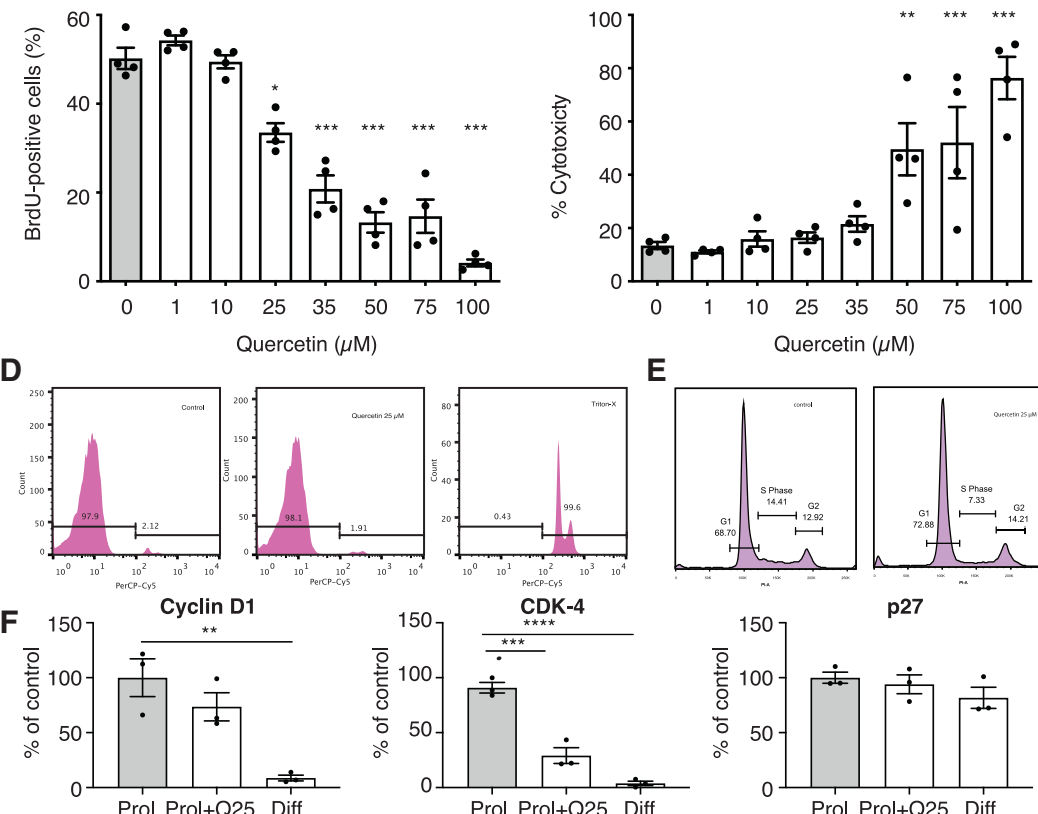

G
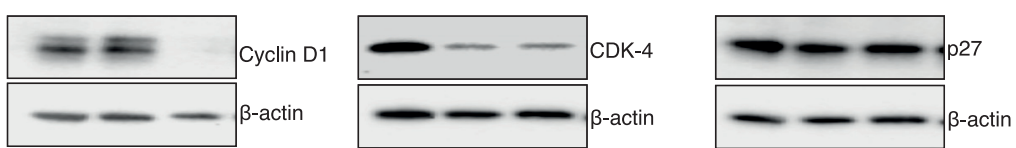

day 0 medium change

day 2 $\mathrm{GF}(20 \mathrm{ng} / \mathrm{ml} \mathrm{bFGF}+\mathrm{EGF})$

H
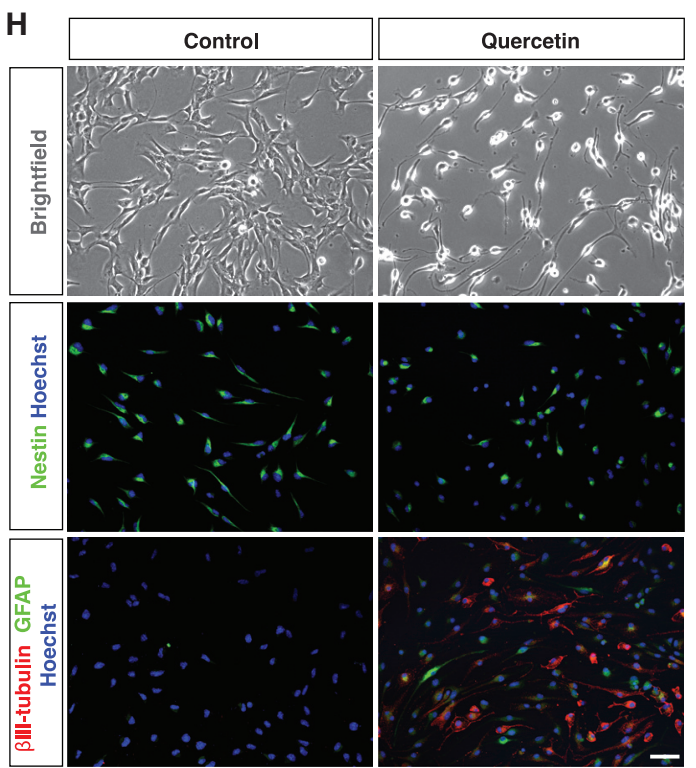

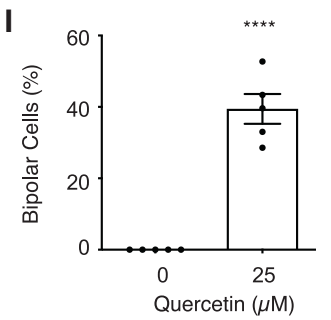

J

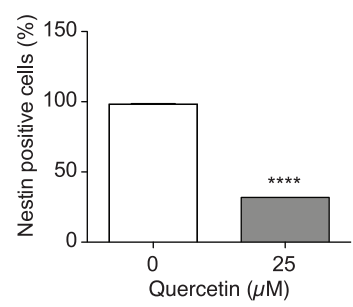

Figure 1. Quercetin Inhibits the Cell Cycle and Induces NPC Differentiation

(A) Schematic of the monolayer NPC culture with $24 \mathrm{~h}$ quercetin treatment.

( $B$ and $C$ ) (B) Quercetin decreased BrdUlabeled cells dose dependently. (C) Quercetin concentrations of $\geq 50 \mu \mathrm{M}$ significantly increased the number of dead cells. $n=4$ independent experiments in (B) and (C).

(D) Cell-cycle analysis using propidium iodide staining revealed a decreased number of cells entering $S$ phase after $24 \mathrm{~h}$ of $25 \mu \mathrm{M}$ quercetin treatment.

(E) 7-AAD staining confirmed that quercetin $(25 \mu \mathrm{M})$ does not induce cell death.

( $F$ and $G$ ) (F) Western blot analysis revealed that quercetin treatment of proliferating precursor cells resulted in the downregulation of CDK4 and no change in the expression levels of cyclin D2 or p27. Cells cultured for $24 \mathrm{~h}$ without growth factors (Diff) were used as a control for cell-cycle arrest. $\mathrm{n}=3$ independent experiments. (G) Experimental scheme.

(H) NPCs develop "neuron-like" bipolar characteristics (top row). In addition, they downregulate nestin expression (middle) and upregulate expression of the neuronal marker $\beta I I I-t u b u l i n$ (bottom). Scale bar, $50 \mu \mathrm{m}$.

(I and J) (I) Quercetin $(25 \mu \mathrm{M})$ significantly increased the percentage of cells with a bipolar morphology. $\mathrm{n}=5$ independent experiments. (J) Quercetin $(25 \mu \mathrm{M})$ significantly decreased the percentage of nestin ${ }^{+}$cells. One-way ANOVA with Dunnett's post hoc test in (B) and (C) and Student's t test in (I) and (J). GF, growth factors. ${ }^{*} p<0.05,{ }^{* *} p<0.01$, $* * * p<0.001, * * * * p<0.0001$. 


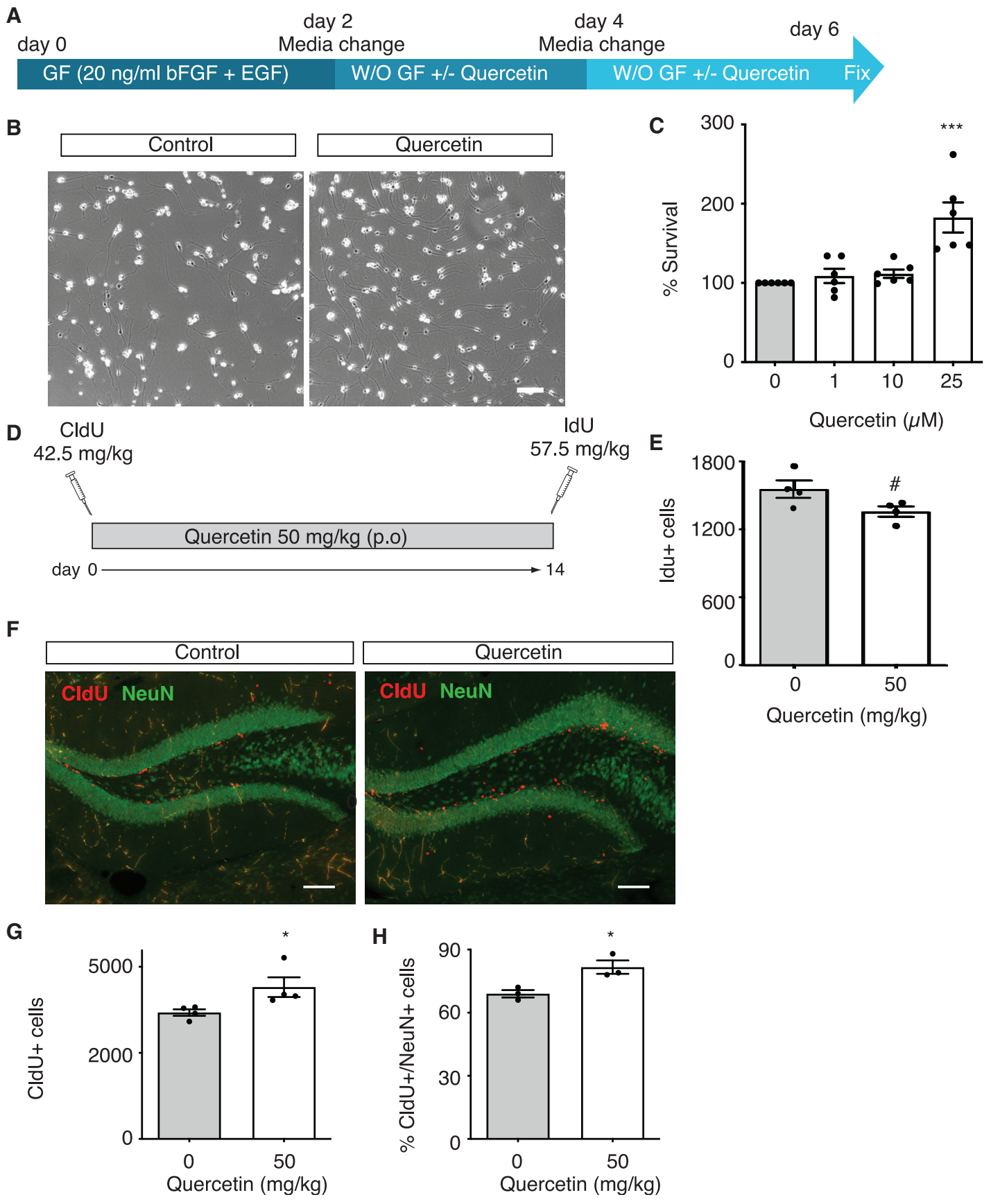

Figure 2. Quercetin Promotes In Vitro Cell Survival and Stimulates Adult Neurogenesis In Vivo

(A) Experimental scheme.

(B) Bright-field images of NPCs $96 \mathrm{~h}$ after growth factor withdrawal.

(C) Quercetin $(25 \mu \mathrm{M})$ increased cell survival during differentiation. Percentage of resazurin fluorescence intensity compared with control. One-way ANOVA with Dunnett's post hoc test, $\mathrm{n}=6$ independent experiments.

(D) Experimental scheme for CldU and IdU injection and quercetin treatment.

$(\mathrm{E}-\mathrm{H})(\mathrm{E}) \mathrm{A}$ trend toward a decrease in $\mathrm{IdU}^{+}$cells was observed in the quercetin-treated animals. (F) Immunofluorescence staining shows the cohort of cells that were $\mathrm{CldU}^{+}$(red) and $\mathrm{NeuN}^{+}$(green). A significant increase in the number of $\mathrm{CldU}^{+}(\mathrm{G})$ and $\mathrm{CldU}^{+} \mathrm{NeuN}^{+}(\mathrm{H}) \mathrm{cells} \mathrm{was}$ observed in the quercetin-treated group. ${ }^{\#} p=0.068 ;{ }^{*} p<0.05,{ }^{* *} p<0.001$, Student's $t$ test, $n=4$ mice per group. Scale bars, $50 \mu \mathrm{m}$. 
A

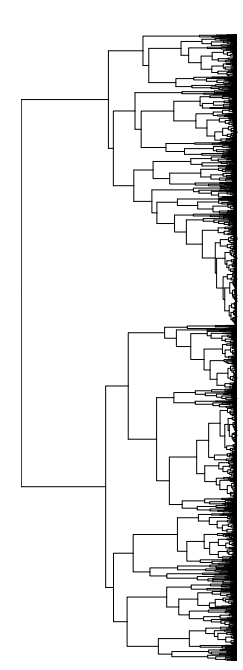

Control

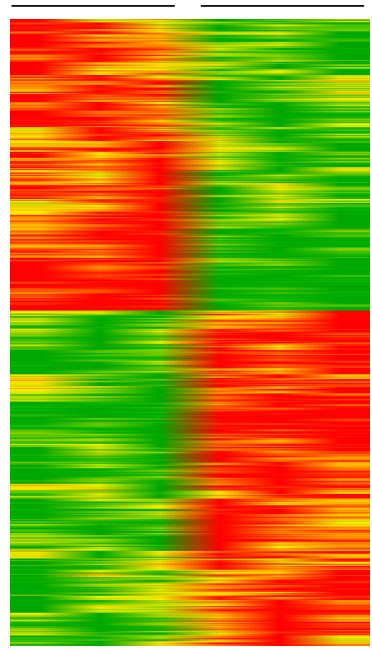

C in genes downregulation by quercetin

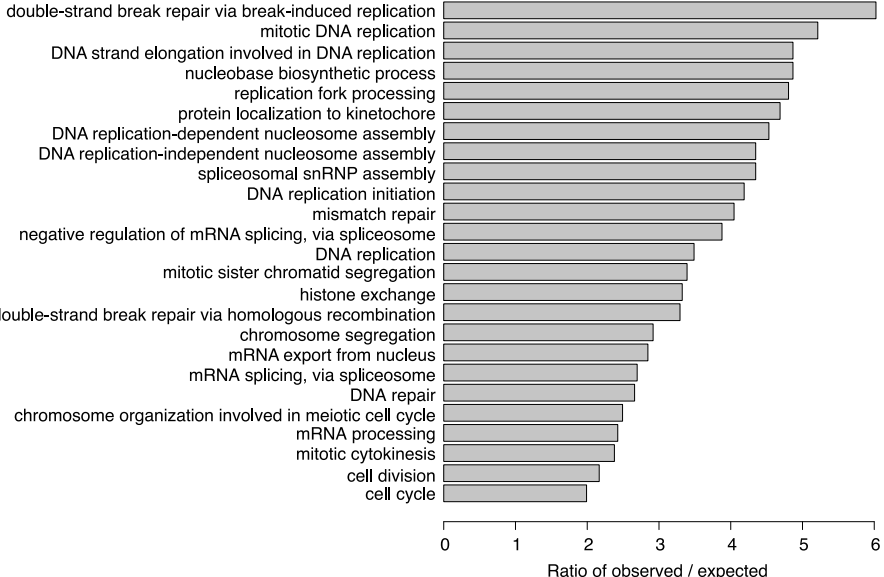

$\mathbf{F}$

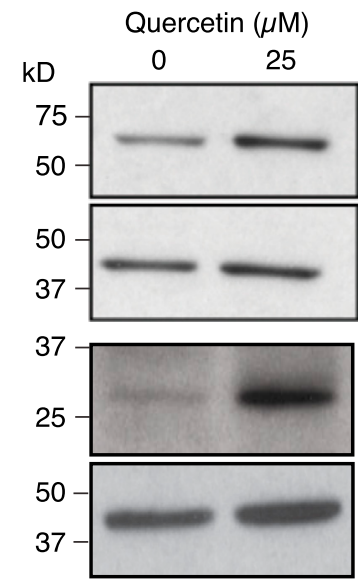

B
Most significantly-enriched GO terms

in genes upregulated by quercetin

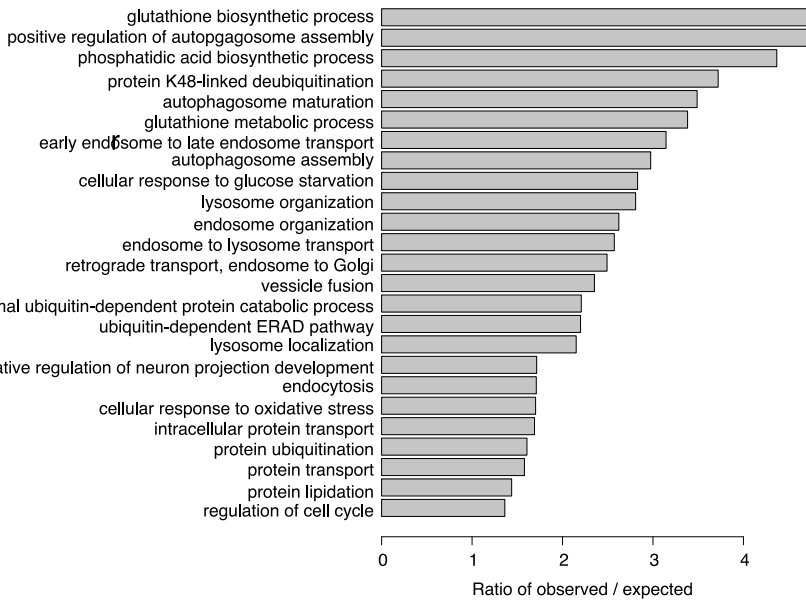

D

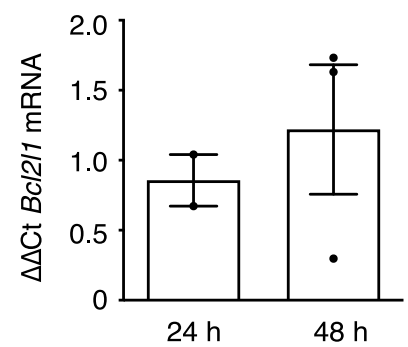

E

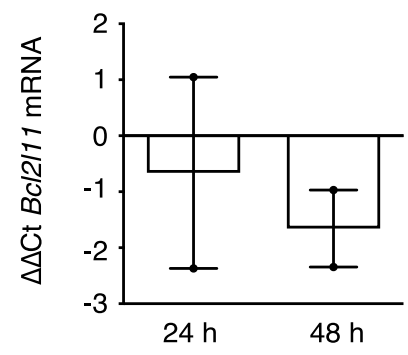

H

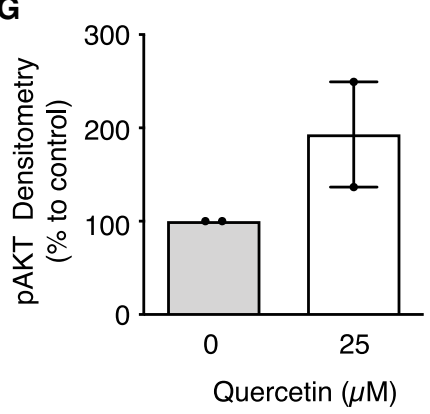

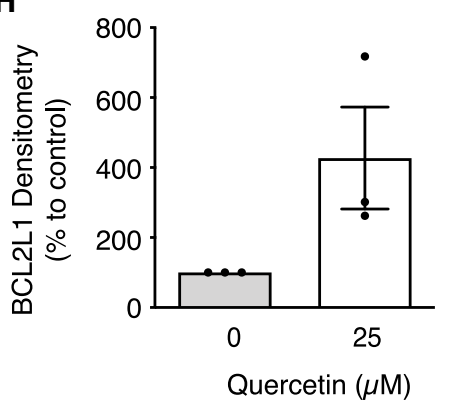

Figure 3. Quercetin Induces Endogenous Antioxidants and the AKT Pathway

(A-E) (A) A heatmap showing changes in NPC transcript expression in cells treated with $25 \mu \mathrm{M}$ quercetin, $24 \mathrm{~h}$ after growth factor withdrawal. The top 25 most enriched pathways from the KEGG database for significantly upregulated (B) or downregulated (C) transcripts. 
pathways (reviewed by Spencer, 2009). The flavonoids were reported to exert their effect on cell survival through modulation of the MAPK and phosphoinositide-3 kinase (PI3KAKT) pathways. The enrichment analysis of the MAPK pathway showed that $\mathrm{p} 42 / 44$ extracellular signal-regulated kinase (ERK) was not differentially expressed in response to quercetin treatment. In contrast, JNK2 and JNK3 were upregulated, whereas JNK1 was downregulated. The transcripts of JNK-related proapoptotic genes, namely Bid, Bax, and Puma, were also upregulated in the quercetintreated group (Table S2). To determine whether the pro-survival and anti-apoptotic signals were simultaneously upregulated, we analyzed the enrichment of the differentially expressed genes in the PI3K-AKT pathway from the KEGG database and the NRF2-Keap1 (kelch-like ECH-associated protein 1) pathway from the WikiPathways database. In the PI3K-AKT pathway we observed significant upregulation of pro-survival genes such as Akt, Creb, $M d m 2$, and BclxL (Bcl2l1). In contrast, apoptosis-inducing genes such as p53 and Bim (Bcl2l11) were downregulated (Table S3).

To confirm the transcriptomic data, we performed qPCR to quantify the expression level of Bcl211 and Bcl2l11. Our results revealed a trend toward Bcl2l1 upregulation over time in the quercetin-treated group (Figure 3D), but a trend toward decreased expression of the pro-apoptotic gene Bcl2l11 (Figure 3E). Increased expression of phospho-AKT (pAKT) and BCL2l1 was also observed at the protein level. After $48 \mathrm{~h}$ incubation with $25 \mu \mathrm{M}$ quercetin, pAKT expression was significantly upregulated (Figures $3 \mathrm{~F}$ and $3 \mathrm{G}$ ). A similar but non-significant pattern was also observed for BCL211 protein expression (Figures $3 \mathrm{~F}$ and $3 \mathrm{H}$ ). Another highly enriched pathway that potentially explains the mechanism via which quercetin promotes the survival of differentiating NPCs is the NRF2-Keap1 pathway. One of the downstream genes in this pathway, Gsta3 (glutathione S-transferase $\alpha 3$ ), was the most highly expressed gene in differentiating NPCs upon $25 \mu \mathrm{M}$ quercetin treatment (Table S4). In addition to Nrf2 upregulation, the Nrf2 antagonist Keap1 was increased in the quercetin-treated group. This increase in Keap1 expression may counteract the detrimental effect of excessive $\mathrm{Nr} 2 \mathrm{2}$ accumulation.

\section{Apple Peel and Flesh Are Pro-neurogenic In Vitro}

Given the above findings with quercetin, we next wanted to determine whether apple peel or flesh displays similar pro-neurogenic properties. We first sought to identify an apple cultivar that is particularly rich in flavonoids by comparing six locally harvested varieties: Elstar, Pinova, Pilot, Rebella, Roter Berlepsch, and Jonagold. Using the borohydride-chloranil assay, we found that these varieties differed greatly in their absolute flavonoid content, although all contained flavonoids in their peel and, to a much lesser extent, in their flesh (Table S5). The enrichment in the peel was greatest (almost 9-fold) in the Pinova cultivar. Using the neurosphere assay, we found that Pinova peel (Figure 4A) and flesh extract (Figure 4A) had a similar pro-neurogenic capacity.

Apple Juice Supplementation Does Not Affect Adult Neurogenesis In Vivo

Given the wide consumption of apple juice, we next examined whether consumption of whole apple juice concentrate affected adult neurogenesis in vivo, with concomitant effects on learning and memory (Figure 4B). To exclude the effect of the increased caloric intake of fruit sugar as a potential confounding factor, a group that received equicaloric sugar water was included in addition to the control group that received normal drinking water. However, all mice showed a similar change in body weight over the experimental period (Figure 4C). Food consumption was greater in mice that drank water compared with mice that received apple juice or equicaloric sugar water (Figure 4D). Liquid consumption differed greatly between the groups, with the highest consumption in the sugar water group (Figure 4E). To detect whether the apple juice supplement had an effect on hippocampus-dependent learning, a reversal version of the Morris water maze task, designed to detect the specific contribution of adult-generated neurons to the overall performance in spatial navigation and cognitive flexibility, was performed (Garthe et al., 2009; Figure 4F). We did not detect any difference between the groups with respect to escape latency (Figure 4G), path length (Figure $4 \mathrm{H}$ ), probe trial performance, or reversal learning (Figures $4 \mathrm{G}$ and $4 \mathrm{H}$ ). Following the behavioral testing, the mice were perfused, and the number of surviving $\mathrm{BrdU}^{+}$cells was quantified. No effect of either the sugar water or the apple juice supplementation on adult hippocampal neurogenesis was observed (Figure 4I).

\section{Apple Flesh Has Pro-neurogenic Activity}

We next returned to our earlier observation that, despite the lower level of flavonoids in apple flesh, there was still as much pro-neurogenic activity as in peel extract. To identify additional pro-neurogenic compounds in apple extracts, we used a bioassay-guided fractionated approach.

Relative expression of the $B c l 2 l 1$ gene increased (D) and the $B c l 2 l 11$ gene decreased (E) in differentiating NPCs after 24 and $48 \mathrm{~h}$ quercetin $(25 \mu \mathrm{M})$ treatment $(\mathrm{n}=3$ experiments).

$(\mathrm{F}-\mathrm{H})$ An increase in the expression of pAKT $(\mathrm{G})$ and $\mathrm{Bcl} 2 \mathrm{l} 1 \mathrm{(H})$ following quercetin treatment was also observed at the protein level ( $F$, western blot). One sample t test, $n=3$ experiments. 


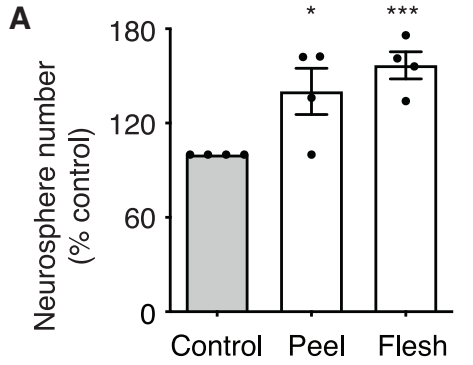

C

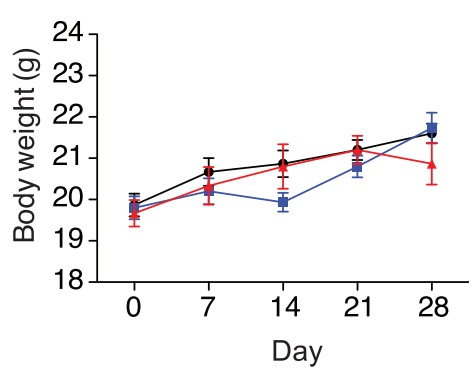

$\mathbf{F}$
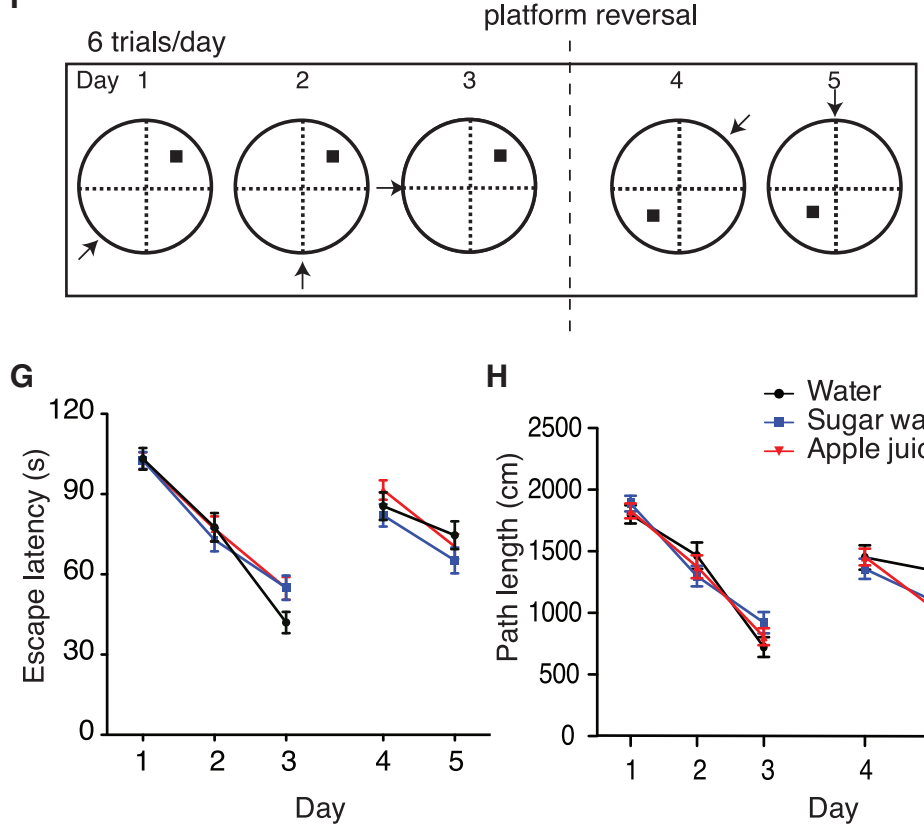

platform reversal

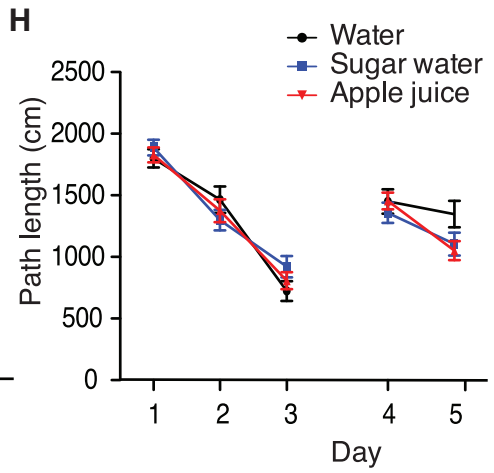

B

BrdU

$50 \mathrm{mg} / \mathrm{kg} \quad$ Apple juice/sugar water supplement

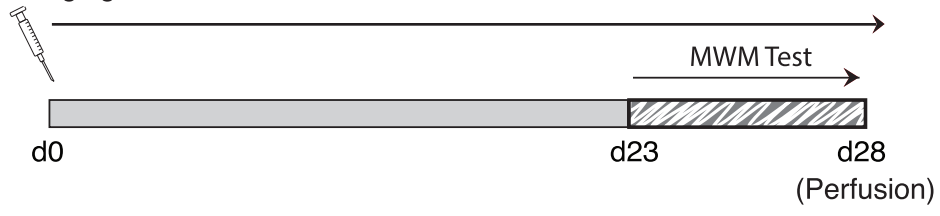

D
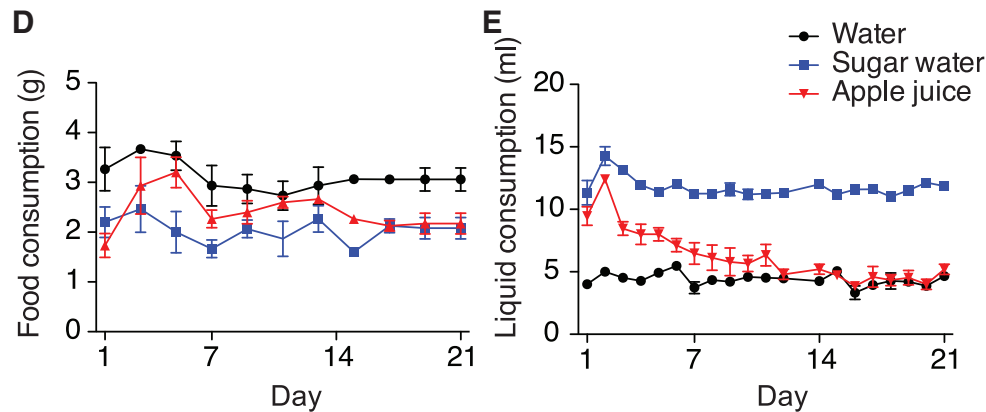

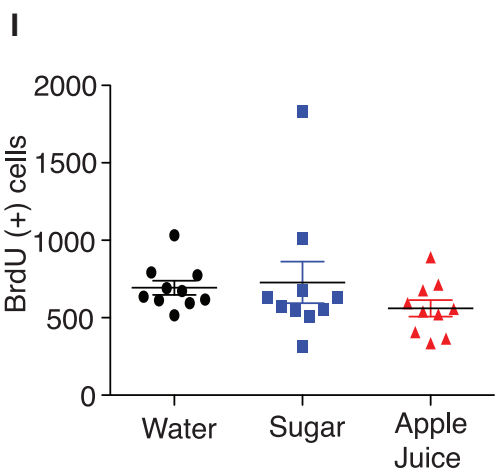

Figure 4. Apple Peel and Flesh Are Pro-neurogenic In Vitro, but Apple Juice Does Not Affect In Vivo Neurogenesis or Cognitive Function

(A) Pinova apple peel and flesh extracts significantly increased the number of primary hippocampal neurospheres. One-way ANOVA with Dunnett's post hoc test.

(B) Experimental scheme for apple juice supplementation. MWM, Morris water maze.

(C) No significant difference in body weight was observed.

(D) The water-supplemented group consumed significantly more food than the apple juice- and sugar water-supplemented mice.

(E) The sugar water-supplemented mice consumed significantly more liquid than the other groups.

(F-I) (F) Experimental scheme. No effect of apple juice or sugar water was observed based on the escape latency $(\mathrm{G})$ or path length (H). No difference in the number of $\mathrm{BrdU}^{+}$cells was observed (I). One-way ANOVA, $\mathrm{n}=10$ mice per group. ${ }^{*} \mathrm{p}<0.05,{ }^{* *} \mathrm{p}<0.001$. 

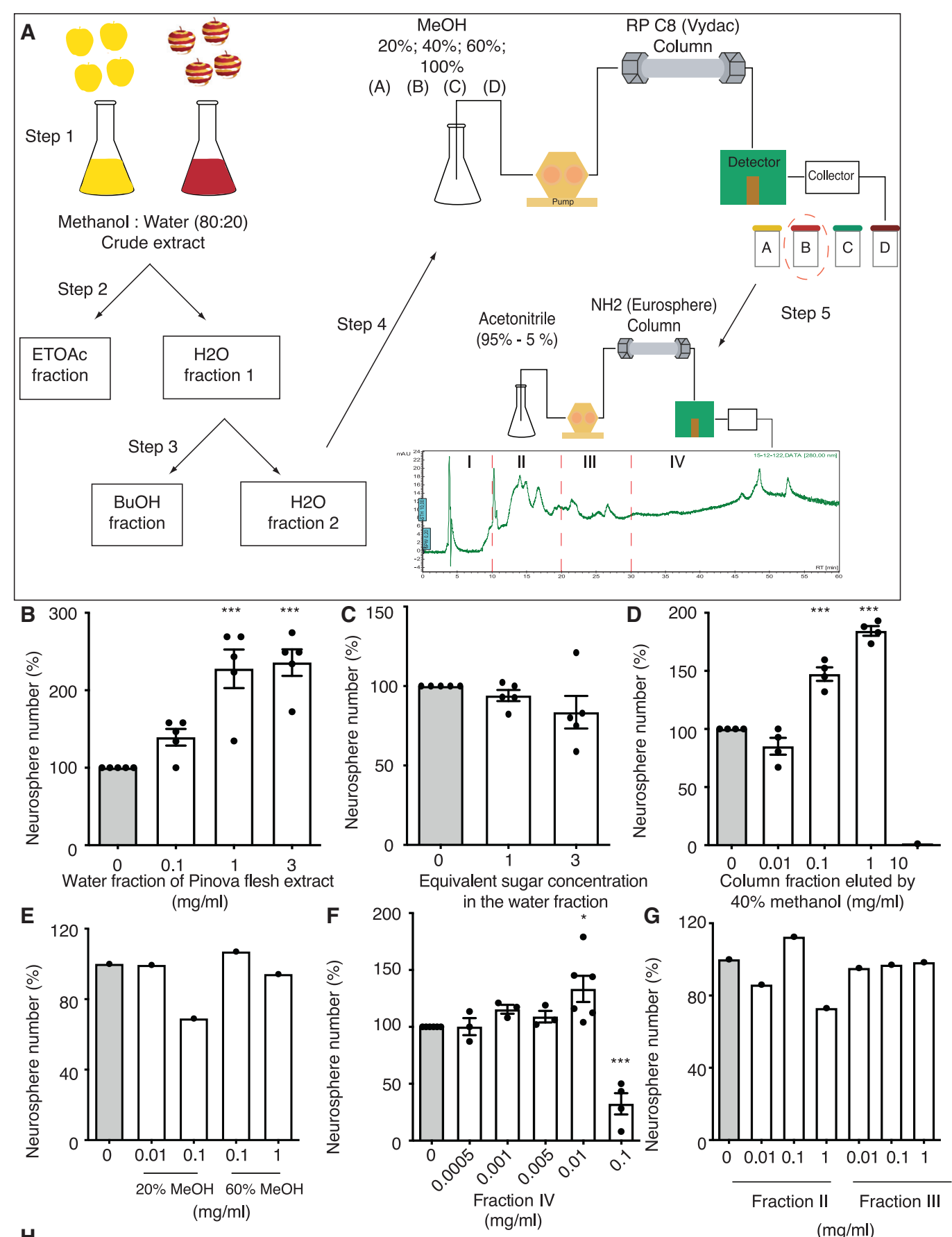

H

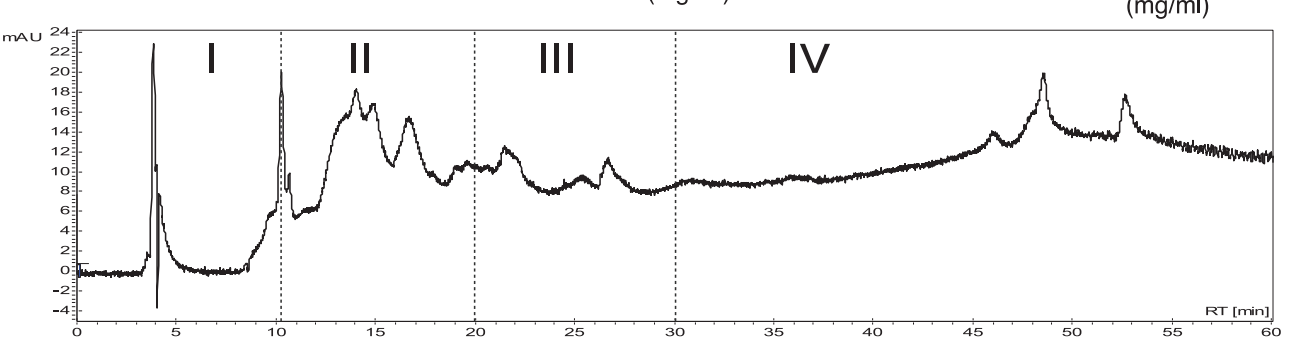

(legend on next page) 
Flesh extract was separated into fractions using liquid- and solid-phase separation methods (Figure 5A). Among the three fractions (water, EtOAc, and $\mathrm{BuOH}$ ), we found a dose-dependent increase in the number of neurospheres generated from primary dentate gyrus cell cultures in the presence of the water fraction, more than doubling the number of neurospheres (Figure 5B). The EtOAc fraction decreased neurosphere counts (0.05 mg/mL 63.2\%, $0.5 \mathrm{mg} / \mathrm{mL} 0 \%$ of control, $\mathrm{n}=1$ experiment). Although there was a small increase in the number of neurospheres generated in the presence of the $\mathrm{BuOH}$ fraction $(0.1 \mathrm{mg} /$ $\mathrm{mL} 128 \%$ of control, $\mathrm{n}=1$ experiment), additional replicates and further fractionation steps could not be performed due to the low yield. As the water fraction also contains fruit sugar that might affect cell growth, we tested a solution with a sugar composition (sucrose, glucose, and fructose) equivalent to that of the water fraction, revealing no effect of sugar on neurosphere numbers (Figure 5C).

The water fraction was next further fractionated by high-performance liquid chromatography in solvents of different polarity (20\%-100\% methanol [MeOH] in water). The 40\% MeOH eluent increased neurosphere number in a dose-dependent manner (Figure 5D), but decreased neurosphere counts at the high concentration of $10 \mathrm{mg} / \mathrm{mL}$. The fractions eluted at $20 \%$ and $60 \% \mathrm{MeOH}$ did not increase neurosphere numbers (Figure $5 \mathrm{E}$ ) and no fraction could be obtained at $100 \% \mathrm{MeOH}$. The $40 \% \mathrm{MeOH}$ fraction was fractionated into four fractions (Figures $5 \mathrm{~F}-5 \mathrm{H}$ ). The neurosphere assay revealed that fraction IV dose-dependently increased the neurosphere count, with a maximum effect at a concentration of $0.01 \mathrm{mg} / \mathrm{mL}$ (Figure 5F). At higher concentrations the number of neurospheres was again decreased. No effect of fraction II or III was observed (Figure 5G).

Fraction IV could not be further sub-fractionated because of the low amount of material. We instead used ultra-performance liquid chromatography coupled with photodiode-array detector and electrospray quadrupole time-of-flight mass spectroscopy (TOF-MS) to identify the compounds present in this fraction. The compounds eluted in the first 1.5 min could not be separated, but subsequent peaks (numbers 1-6; Figure 6A) were subjected to TOF-MS and collision-induced dissociation. Interestingly, two of the peaks were identified as the glycosides of dihy- droxybenzoate (Table S6), the salt of dihydroxybenzoic acid (DHBA), which belongs to the non-flavonoid phenolic compounds present in fruits. We therefore obtained commercially available isomers of DHBA and examined their effects on NPC activity. A significant increase in neurosphere numbers was found with 2,3-DHBA at a concentration of $1 \mu \mathrm{M}$ (Figure $6 \mathrm{~B}$ ) and 3,5-DHBA at concentrations of 1 and $10 \mu \mathrm{M}$ (Figure 6D). Treatment with $1 \mu \mathrm{M} 3,4-\mathrm{DHBA}$ produced a slight increase in the number of neurospheres generated ( $\mathrm{p}=0.19$; Figure $6 \mathrm{C}$ ), whereas $10 \mu \mathrm{M} 3,5-\mathrm{DHBA}$ led to a significant increase in neurosphere number (Figure $6 \mathrm{E}$ ) as well as a significant increase in neurosphere size (Figure 6F). We also found that treatment of adherent monolayer cultures with 3,5-DHBA at concentrations of 100 and $250 \mu \mathrm{M}$ resulted in a higher cell density after 4 days in culture (Figure 6G). To determine whether this was due to 3,5-DHBA acting on NPC survival when cultured under proliferation conditions, adherent cells were cultured in growth factors for 4 days and varying concentrations of 3,5-DHBA were added on day 0 ( 4 day), day 2 ( 2 day), or day 3 ( 1 day), after which the resazurin cell viability assay was performed on day 4 (Figure $6 \mathrm{H}$ ). Our results revealed an increase in the percentage of cell survival at the higher 3,5-DHBA concentrations, with the strongest effect size observed when the 3,5-DHBA was present in the medium for the entire 4 days of the experiment (Figures 6I$6 \mathrm{~K})$. We also examined whether 3,5-DHBA had a similar cell survival effect when the adherent NPCs were cultured under differentiation conditions (Figure 6L). Again we observed a neuroprotective effect, with a significant increase in cell survival found in the cells treated with 3,5DHBA $(\geq 250 \mu \mathrm{M})$ throughout the entire differentiation process (Figure $6 \mathrm{M}$ ). After 6 days of differentiation these cells were fixed and stained for markers of mature neurons and astrocytes. We found a significantly higher percentage of $\beta$ III-tubulin ${ }^{+}$neurons in the cultures differentiated in the presence of high concentrations of 3,5-DHBA, further confirming its pro-neurogenic effect (Figures 6N and 6O).

HCAR1, the Putative Receptor for Hydroxybenzoic Acid, Is Expressed on NPCs and in the Neurogenic Niche In Vivo

The hydroxycarboxylic acid receptor 1 (HCAR1) had been listed as an orphan receptor until it was identified as the

Figure 5. Apple Flesh Extracts Display Pro-neurogenic Activity

(A) Experimental scheme for the extraction and fractionation of apple extract.

$(B-H)(B)$ The water fraction of Pinova flesh extract significantly increased the number of hippocampal neurospheres, whereas (C) the equivalent concentration of sugar had no effect; $n=5$ independent experiments. Following further separation of the water fraction, (D) the $40 \%$ methanol-eluted fraction significantly increased the number of hippocampal neurospheres ( $n=4$ experiments), whereas ( $E$ ) the $20 \%$ and $60 \%$ methanol fractions had no effect $(n=1$ experiment). Following further fractionation of the $40 \%$ methanol fraction, the proneurogenic activity was restricted to fraction IV ( $F$, fraction IV; $G$, fractions II and III; $n=3$ individual experiments; $H, H P L C$ elution trace). One-way ANOVA with Dunnett's post hoc test. ${ }^{*} p<0.05,{ }^{* *} p<0.001$. 
A

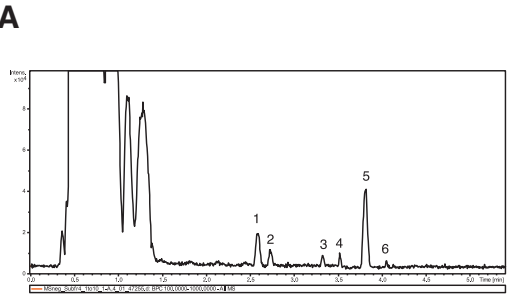

B

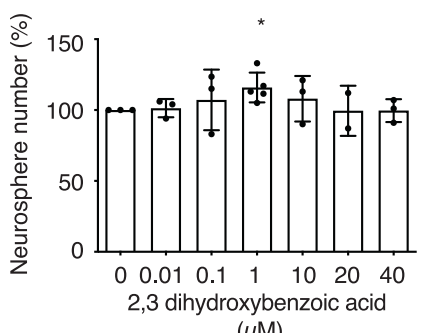

$(\mu \mathrm{M})$

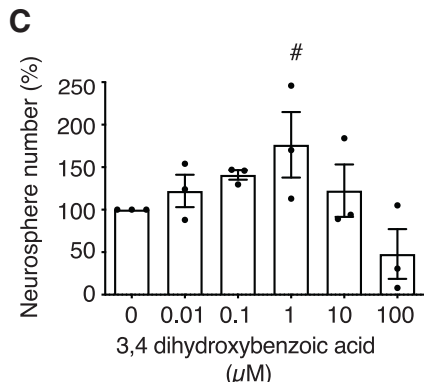

$(\mu \mathrm{M})$
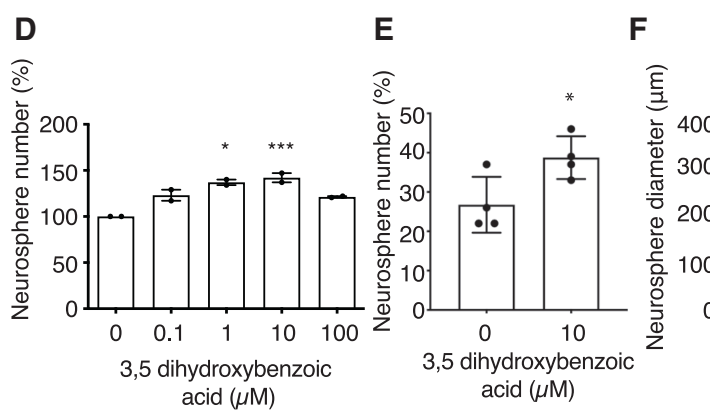

acid $(\mu \mathrm{M})$
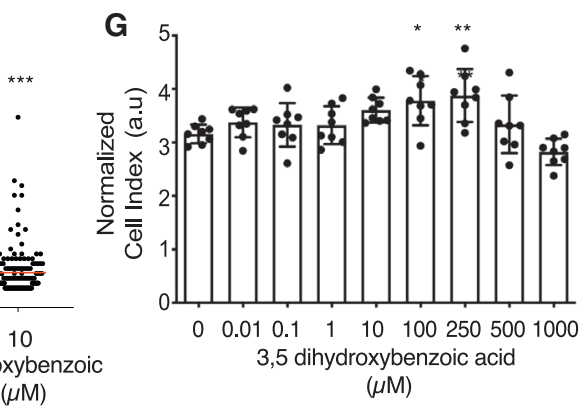

H
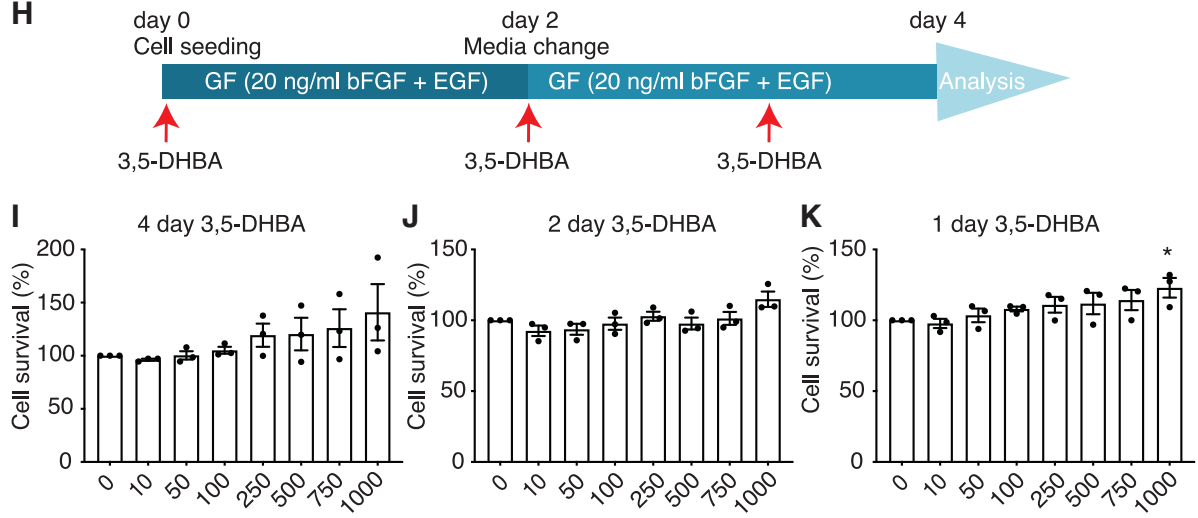

3,5 dihydroxybenzoic acid

3,5 dihydroxybenzoic acid $(\mu \mathrm{M})$

3,5 dihydroxybenzoic acid

$\mathbf{L}$

$$
(\mu \mathrm{M})
$$

day 2

$$
(\mu \mathrm{M})
$$

$$
\text { Cell seeding Media change day } 4
$$
$\mathrm{GF}(20 \mathrm{ng} / \mathrm{ml} \mathrm{bFGF}+\mathrm{EGF})$ GF $(5 \mathrm{ng} / \mathrm{ml} \mathrm{bFGF}+\mathrm{EGF})$

3,5-DHBA

3,5-DHBA

3,5-DHBA

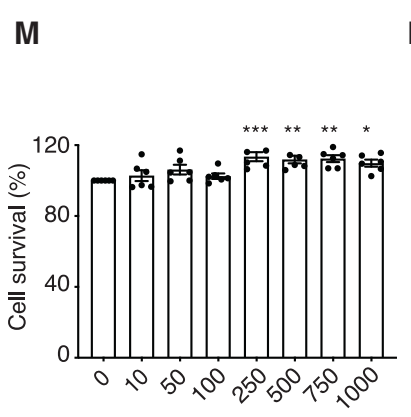

3,5 dihydroxybenzoic acid $(\mu \mathrm{M})$
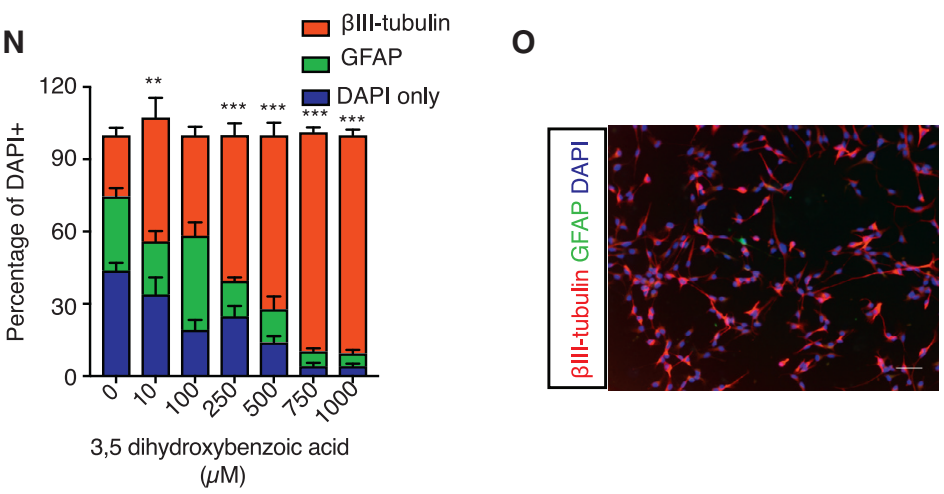

(legend on next page) 
receptor for lactate and 3,5-DHBA. HCAR1 is expressed in the brain, including in the hippocampus (Castillo et al., 2015). Using immunocytochemistry we confirmed that HCAR1 was expressed by proliferating nestin ${ }^{+} /$Sox $^{+}$hippocampal adherent monolayer cells in vitro (Figure $7 \mathrm{~A}$ ). Immunofluorescence staining of brain sections revealed that, in addition to being expressed by the granular cells of the dentate gyrus, as has been previously reported (Castillo et al., 2015), HCAR1 is also expressed by type 1 and type 2 NPCs, as evidenced by the co-expression of nestin and Sox2 (Figure 7B).

\section{3,5-DHBA Increases NPC Proliferation and}

\section{Neurogenesis In Vivo}

Given the positive effects of 3,5-DHBA on NPC proliferation and survival in vitro, and the presence of HCAR1 on NPCs in vivo, we finally examined whether administration of 3,5-DHBA affects in vivo NPC proliferation and adult neurogenesis. To do this, 3,5-DHBA (15.625, 31.25, 62.5, 125 , and $250 \mathrm{mg} / \mathrm{kg}$ ) was administered intraperitoneally to adult mice once daily for 14 days prior to perfusion. A group that received no DHBA, but had free access to a running wheel, was included as a positive control. All mice received two intraperitoneal injections of BrdU (50 $\mathrm{mg} / \mathrm{kg}$ ) spaced $1 \mathrm{~h}$ apart prior to the first dose of 3,5DHBA to label the proliferating cells. Treatment with 3,5DHBA resulted in a significant increase in the number of proliferating NPCs in the subgranular zone of the dentate gyrus in all but the group receiving the highest dose of 3.5-DHBA, with the greatest effect being observed at a dose of $62.5 \mathrm{mg} / \mathrm{kg}$ (Figures 7C and 7D). A similar result was observed following quantification of the number of BrdU-labeled cells (Figures 7E and 7F). Finally, the number of immature neurons $\left(\mathrm{DCX}^{+}\right)$was counted to determine whether, in addition to proliferation, 3,5-DHBA treatment also influences adult neurogenesis. Similar to the results obtained for the in vitro experiments, we observed a significant increase in the number of newborn neurons in all but the group receiving the highest dose of 3,5-DHBA, with the greatest increase observed in the group receiving $62.5 \mathrm{mg} / \mathrm{kg}$ (Figures $7 \mathrm{G}$ and $7 \mathrm{H}$ ). To examine whether 3,5-DHBA treatment also affected the maturation rate of the newborn neurons, the $\mathrm{DCX}^{+}$cells were morphologically categorized according to the presence and shape of their apical dendrites (Plumpe et al., 2006). Briefly, category $A$ and B cells had no or very short processes, $C$ and D cells had increasingly longer processes that, by stage D, had reached the molecular layer, and category E cells had one strong dendrite with sparse branching, whereas in category F cells the dendritic tree was more elaborate, with multiple branches in the molecular cell layer. We found that the mice treated with $62.5 \mathrm{mg} / \mathrm{kg} 3,5$-DHBA had both a significantly higher percentage and a significantly higher absolute number of $\mathrm{DCX}^{+}$cells belonging to categories $\mathrm{E}$ and $\mathrm{F}$ than the control mice, indicating that 3,5-DHBA treatment increases the maturation speed of the newly born neurons (Figures 7I and 7J). Interestingly, and consistent with our previous report (Plumpe et al., 2006), this change in dendritic morphology was not observed in the positive control group of mice that exercised.

\section{DISCUSSION}

In this study we demonstrate that apples contain proneurogenic compounds in both their peel and their flesh. Our data reveal that, while quercetin is anti-proliferative at high concentrations, its effect on NPCs at lower concentrations is more complex and appears to involve activation rather than inhibition. We found that $25 \mu \mathrm{M}$ quercetin

Figure 6. Hydroxybenzoic Acid Is a Pro-neurogenic Compound Found in Apple Flesh

(A-E) (A) Base peak chromatogram m/z 100-1000, gradient elution, electrospray ionization(-) of fraction IV. Six peaks. were annotated, two of which (peaks 2 and 4) were glycosides of dihydrobenzoate. Neurosphere assays revealed that the dihydroxybenzoic acid isomers (B) 2,3-DHBA, (C) 3,4-DHBA, and (D and E) 3,5-DHBA all increased precursor proliferation, with the greatest effect observed in response to 3,5 -DHBA. $n=2-5$ individual experiments. ${ }^{\#} p=0.19$.

(F) In addition to increasing neurosphere number, 3,5-DHBA also significantly increased the diameter of the resulting neurospheres.

(G) Using the XCELLigence impedance-based assay, an increased number of cells were detected in adherent monolayer cultures treated with 100 and $250 \mu$ M 3,5-DHBA. $\mathrm{n}=8$ independent experiments.

(H) Adherent cells were cultured in $20 \mathrm{ng} / \mathrm{mL}$ epidermal growth factor (EGF) and basic fibroblast growth factor (bFGF) for 4 days and varying concentrations of 3,5-DHBA were added on day 0,2 , or 3 . The resazurin assay was then performed on day 4.

(I-K) An increase in the percentage of cell survival at the higher 3,5-DHBA concentrations was observed. (I) 4 day, (J) 2 day, (K) 1 day. $\mathrm{n}=3$ independent experiments.

(L) Adherent precursor cells were cultured under differentiation conditions with 3,5-DHBA present throughout the experiment.

(M) A significant increase in cell survival was observed in the differentiating cells treated with $\geq 250 \mu \mathrm{M} 3,5$-DHBA. $\mathrm{n}=6$ independent experiments.

( $\mathrm{N}$ and 0 ) (N) 3,5-DHBA dose-dependently increased the number of surviving differentiated neurons, with the highest effect observed (0) in the cultures treated with $1,000 \mu \mathrm{M} 3,5-\mathrm{DHBA}$.

One-way ANOVA with Dunnett's post hoc and Student's t test (E and F). Scale bar in (0), $50 \mu \mathrm{m} .{ }^{*} p<0.05,{ }^{* *} p<0.01,{ }^{* * *} p<0.001$. 

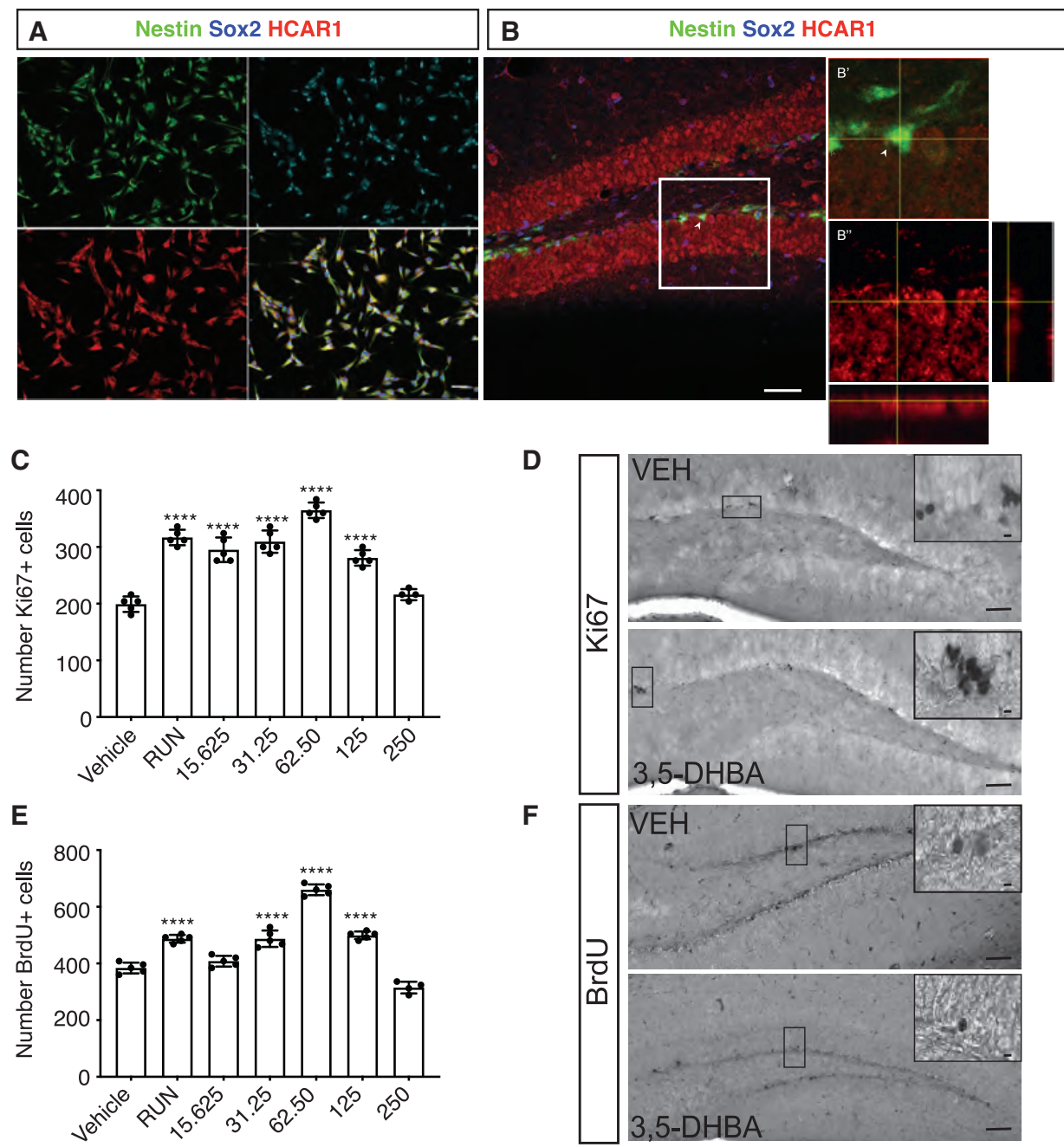

G

H
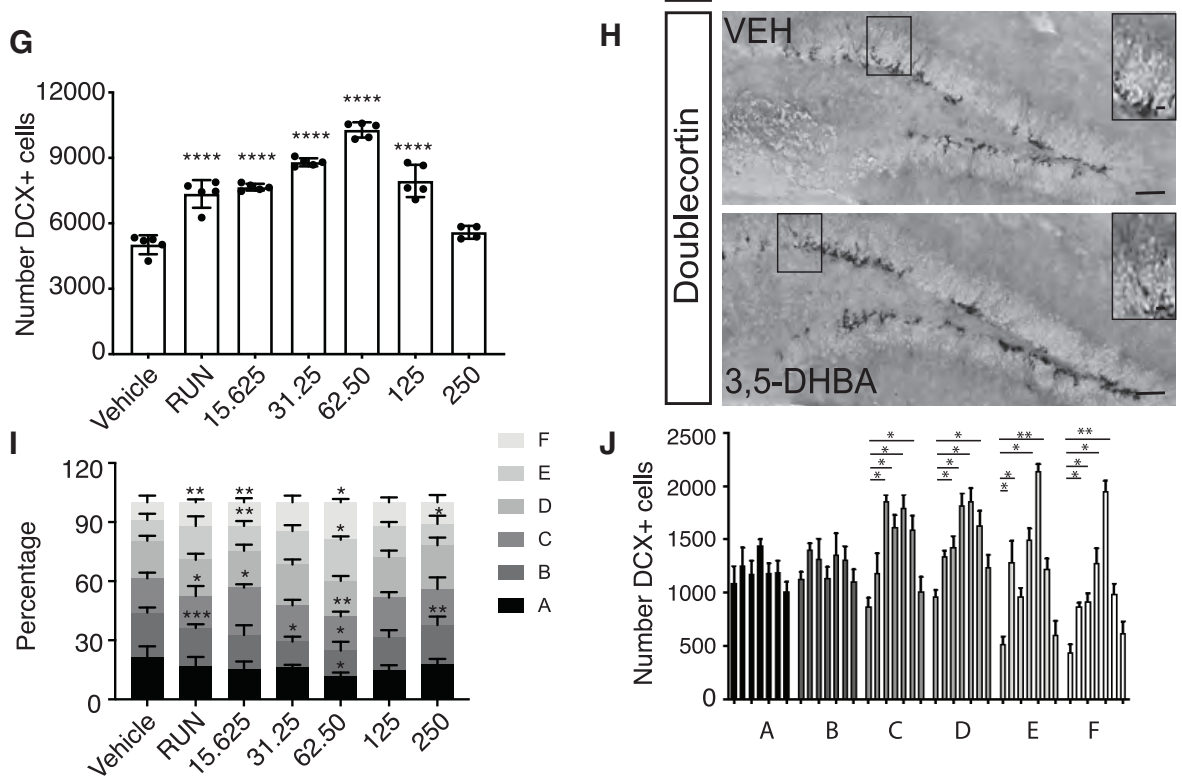

(legend on next page) 
increased cell-cycle exit and promoted the survival and differentiation of adult hippocampal NPCs, both ex vivo and in vivo. This is similar to the effect that we and others have previously reported for compounds such as resveratrol and EGCG (Ortiz-Lopez et al., 2016; Torres-Perez et al., 2015; Yoo et al., 2010). Natural compounds such as these, which are abundant in widely consumed fruits and vegetables, might therefore contribute to a beneficial effect on neurogenesis and brain function as part of broader environmental influences.

Based on transcriptomic data we propose that the PI3KAKT and NRF2-KEAP1 pathways are involved in such effects. This is in agreement with previous reports that flavonoids have numerous modes of action. Under stress conditions, there is an activation and accumulation of NRF2 in the nucleus (Nguyen et al., 2009). The heterodimer of NRF2 with small MAF (musculoaponeurotic fibrosarcoma) has been shown to increase the binding affinity with ARE, which leads to the transcription of phase II enzymes (Itoh et al., 1997). These enzymes play important roles in endogenous protection systems by neutralizing the harmful by-products of oxidative stress (Nguyen et al., 2003). A downstream gene in this pathway, Gsta3, was the most highly expressed gene in differentiating NPCs after $25 \mu \mathrm{M}$ quercetin treatment. In addition to Nrf2 upregulation, Keap1 was also upregulated in the quercetin-treated group. This protein facilitates the nucleocytoplasmic shuttling mechanism of Nrf2 and subsequently promotes its ubiquitinoylation and degradation (Nguyen et al., 2005). Bell and colleagues demonstrated that the overexpression of NRF2 inhibits neurite outgrowth and neuronal maturation (Bell et al., 2015). It is therefore likely that the upregulation of KEAP1 expression in response to quercetin treatment counteracts the detrimental effect of excessive NRF2 accumulation.

Given the pro-neurogenic nature of quercetin, we sought to determine whether apple extracts display similar properties. We found that apple extracts from the flesh and to a lesser extent the peel increased neuro- sphere formation in vitro. Previous studies in aged animals found that apple supplementation prevented oxidative brain damage through increased endogenous antioxidative capacity, as well as restoring long-term potentiation and acetylcholine level, concurrent with improvement in behavioral tasks (Tchantchou et al., 2005; Viggiano et al., 2006). A pilot human study showed that the consumption of apple juice improved behavioral symptoms in patients with Alzheimer's disease (Remington et al., 2010). However, no significant cognitive change was observed after short-term apple supplementation in healthy volunteers (Bondonno et al., 2014). We therefore investigated whether apple juice consumption could increase neurogenesis and enhance spatial learning and memory in mice. Despite observing pro-proliferative effects of apple extract in vitro, we found no effect of apple juice consumption on in vivo neurogenesis or spatial learning and memory performance. Given that the quercetin concentration in apple juice is very low (below $2 \mathrm{mg} / \mathrm{L}$ ), resulting in an intake of approximately $0.6 \mathrm{mg} /$ $\mathrm{kg}$, we conclude that this is likely an insufficient concentration of active phytochemical to modulate neurogenesis with a measurable effect size. This, however, does not exclude a contributing effect to overall environmental effects on brain function.

Interestingly, we identified DHBA as a pro-neurogenic factor unrelated to flavonoids. Hydroxybenzoic acid is abundant in fruits, where it acts as a natural preservative (Soni et al., 2005). Multiple bioactive molecules are structurally related to 3,5-DHBA (Hubkova et al., 2014), some of which (e.g., 3-HBA) also bind to the HCA2 receptor, whereas 3,5-DHBA specifically, albeit weakly, binds to HCAR1 (Liu et al., 2012). Interestingly, HCAR1 is a Gicoupled receptor, which, after activation, inhibits adenylate cyclase to downregulate formation of cyclic adenosine monophosphate (cAMP) (Liu et al., 2012). Biochemical studies have revealed that 3,5-DHBA shows a higher potency to decrease the levels of cAMP in SK-N-MC cells than lactate, the natural ligand of HCAR1 (Liu et al.,

Figure 7. 3,5-DHBA Increases Neural Precursor Cell Proliferation and Neurogenesis In Vivo

(A) Immunofluorescence staining of proliferating adult hippocampal precursor cells in monolayer culture. HCAR1 (red) co-localized with the neural precursor cell markers nestin (green) and Sox2 (cyan).

(B-H) (B) Confocal z-stack image of the hippocampal dentate gyrus in brain sections from nestin-GFP mice. HCAR1 (red), nestin (green), and Sox2 (dark blue). Arrowhead points to a nestin ${ }^{+}$cell with HCAR1 co-localization confirmed in orthogonal view ( $\left.\mathrm{B}^{\prime \prime}\right)$. In vivo administration of 3,5-DHBA resulted in a significant increase in the number of proliferating $\left(\mathrm{Ki}^{+} 7^{+}\right)$cells $(\mathrm{C}, \mathrm{D}), \mathrm{BrdU} \mathrm{U}^{+}$cells $(\mathrm{E}, \mathrm{F})$, and $\mathrm{DCX} \mathrm{X}^{+}$ immature neurons $(G, H)$ in the dentate gyrus. $n=5$ animals per group.

(I) 3,5-DHBA administration altered the dendritic morphology of the newly born neurons, increasing the percentage of DCX ${ }^{+}$cells with a more mature phenotype.

(J) 3,5-DHBA administration also increased the absolute number of DCX+ cells with a mature morphology (DCX classes C-F). For each DCX+ cell class the bars are vehicle, RUN, and 15.625, 31.25, 62.5, 125, and $250 \mathrm{mg} / \mathrm{kg} \mathrm{3,5-DHBA}$ from left to right.

One-way ANOVA with Dunnett's post hoc test in (C, E, and G) and two-way ANOVA with Tukey post hoc test in (I and J). Scale bars, $150 \mu \mathrm{m}$ and, for the insets, $15 \mu \mathrm{m} .{ }^{*} p<0.05,{ }^{* *} p<0.01,{ }^{* * *} p<0.001,{ }^{* * * *} p<0.0001$. 
2012). 3,5-DHBA is also more potent than lactate in hippocampal slices (Liu et al., 2012).

Although the food industry uses benzoic acid as a preservative, naturally occurring DHBA has received relatively little attention as a potential signaling molecule. DHBA binds to the lactate receptor, GPR81/HCAR1 (Cai et al., 2008), which, as we show, is present on NPCs, suggesting a direct mode of action. At the same time, given the role of lactate as both a signaling molecule and a source of energy for neurons, the discovery of an intrinsically active agonist to the receptor on neural stem cells is of further relevance (LevVachnish et al., 2019; Wang et al., 2019). We found that 3,5-DHBA not only increases NPC proliferation and neurogenesis, but also increases the maturation rate of these newborn cells. This appeared to be a concentration-dependent effect, with the most effective dose being $62.5 \mathrm{mg} / \mathrm{kg}$ and no effect observed at the highest concentration tested (250 mg/kg). In accordance with our results, another study also observed that administration of high concentrations of 3,5-DHBA had no effect on the long-term survival of newly born neurons (Lev-Vachnish et al., 2019). However, in that study lower concentrations of DHBA were not examined. Thus, the observation of a dose-dependent response to 3,5-DHBA is interesting, as it might indicate differential regulation and a modulatory effect. Little is known about downstream signaling events after HCAR1 activation. However, in muscle myotubes, 3,5-DHBA has been shown to stimulate phosphorylation of MAPK kinase 1/2 (MEK1/2), ERK1/2, and p90 ribosomal S6 kinase (p90RSK) (Ohno et al., 2018). In hippocampal neurons, 3,5-DHBA also affects energy metabolism, ion homeostasis, and (possibly directly) synaptic signaling (Angamo et al., 2016).

We have shown that both flavonoids and DHBA are proneurogenic, not only by activating NPC proliferation but also by promoting cell-cycle exit, cellular survival, and neuronal differentiation. An obvious caveat of our approach is the limitation of the in vitro experiment. Both quercetin and isoforms of DHBA have been used as targeting moieties to facilitate drug delivery across the bloodbrain barrier (Guo et al., 2020; Pinto et al., 2020). Therefore, although our in vivo experiments cannot distinguish direct from indirect effects, the ex vivo studies indicate that direct effects are generally possible.

\section{EXPERIMENTAL PROCEDURES}

\section{Animals}

Male and female C57BL/6JRj mice were purchased from Janvier and experiments were conducted in accordance with the applicable European (86/609/EEC) and national (Tierschutzgesetz) regulations and approved by the local ethics committee (DD24-5131/ 207/27). The C57BL/6NHsd mice were purchased from Harlan
Laboratories (Mexico City) and BALB/c mice were obtained from the animal facility of the National Institute of Psychiatry "Ramón de la Fuente Muñiz," with experiments conducted in accordance with the national regulations (NOM-062-ZOO-1999) and approved by the local ethics committee (CEI/C/009/2013). Mice were housed in standard laboratory cages ( 4 or 5 mice per cage) under a $12 \mathrm{~h}$ light/12 $\mathrm{h}$ dark cycle at a temperature of $23^{\circ} \mathrm{C} \pm 1^{\circ} \mathrm{C}$. The animals had ad libitum access to food and water.

\section{In Vivo Quercetin Treatment}

CldU $(42.5 \mathrm{mg} / \mathrm{kg})$ was injected at the beginning of the experiment and IdU $(57.5 \mathrm{mg} / \mathrm{kg})$ was injected $2 \mathrm{~h}$ before the animals were perfused with $4 \%$ paraformaldehyde (PFA). Quercetin $(50 \mathrm{mg} / \mathrm{kg}$; Sigma) was prepared fresh in propylene glycol and administered daily through oral gavage (total volume $200 \mu \mathrm{L}$ ).

\section{In Vivo Apple Juice Supplementation}

Pinova apples were purchased from Obsthof Schlage Dresden-Pillnitz, harvested in autumn 2014. Eight liters of apple juice was obtained from $13 \mathrm{~kg}$ of fresh apples, then aliquoted, and stored at $-80^{\circ} \mathrm{C}$. Mice were housed in groups of five that received juice, sugar water, or normal drinking water. The sugar water or apple juice was replaced daily. Food and liquid intake was measured daily and body weight was measured weekly. A single injection of BrdU $(50 \mathrm{mg} / \mathrm{kg}$ ) was given on the first day of the experiment and the mice were perfused 1 day after the completion of the water maze task.

Isolation of Adult Hippocampal Neural Precursor Cells The isolation procedure for adult hippocampal NPCs was adapted from Babu et al. (2007). Mice were killed by cervical dislocation, the brains were collected, and the dentate gyrus was dissected as previously described (Walker and Kempermann, 2014). The tissue was dissociated using a Neural Dissociation Kit-P (Miltenyi Biotec) and the cells were resuspended in $1 \mathrm{~mL}$ of growth medium (Neurobasal medium containing 2\% B27 supplements, $1 \times$ GlutaMAX, $2 \mu \mathrm{g} / \mathrm{mL}$ heparin, 50 units/mL penicillin/streptomycin, $20 \mathrm{ng} /$ $\mathrm{mL}$ epidermal growth factor (EGF) and $20 \mathrm{ng} / \mathrm{mL}$ basic fibroblast growth factor (bFGF-2)). The cells were then plated into one well of a PDL- and laminin-coated 12 well plate and incubated in $37^{\circ} \mathrm{C}, 5 \% \mathrm{CO}_{2}$, for monolayer cultures, or into an uncoated 96 well plate for neurosphere cultures. The tested compounds/extracts were dissolved in water or DMSO, depending on the solubility. When DMSO was used as the vehicle, the final concentration in the culture medium did not exceed $0.1 \%$ and an equivalent volume of DMSO was added to control conditions.

\section{Adherent Monolayer Cell Culture}

Five or six male and female C57BL/6JRj mice were used to establish a monolayer culture. After tissue dissociation, the NPCs were plated into a $\mathrm{PDL} /$ laminin-coated plate and incubated at $37^{\circ} \mathrm{C}$ with $5 \% \mathrm{CO}_{2}$. Every second day, half of the medium was replaced with fresh proliferation medium containing $20 \mathrm{ng} / \mathrm{mL}$ bFGF and $20 \mathrm{ng} / \mathrm{mL}$ EGF. After reaching 80\% confluency, the cells were passaged and replated at a density of 10,000 cells $/ \mathrm{cm}^{2}$. This was repeated until passage 6 , after which the cells were cryopreserved in vials each containing $1 \times 10^{6}$ cells. For each of the adherent 
monolayer culture experiments, a vial of stock cells was thawed and plated into a T25 flask containing proliferation medium. The cells were passaged at least once before being plated into at least three replicate wells of a PDL/laminin-coated 24 well plate and treated as described in each individual experiment. This constituted an $n=1$ and was repeated an additional three or four times on subsequent passages to provide the data described as $n=3$ or 4 individual experiments for each dataset. The cells used for experiments did not exceed passage 15 .

\section{Neurosphere Assay}

Freshly isolated NPCs from the dentate gyrus were resuspended in complete neurosphere medium to reach the approximate density of two hippocampi in $10 \mathrm{~mL}$ medium, and subsequently filtered through a $40 \mu \mathrm{m}$ nylon mesh cell strainer (Walker and Kempermann, 2014). After the test compounds or vehicle was added, the cells were plated in a 96 well plate and incubated at $37^{\circ} \mathrm{C}$, $5 \% \mathrm{CO}_{2}$ for 12 days. Neurospheres with diameters $\geq 40 \mu \mathrm{m}$ were counted using an inverted light microscope.

\section{Cell-Cycle Analysis with Propidium Iodide Staining}

Cells were harvested and fixed with ice-cold $70 \%$ ethanol. Following two PBS washes, the cell pellet was treated with $50 \mu \mathrm{L}$ RNase A $(100 \mu \mathrm{g} / \mathrm{mL})$. Subsequently, $400 \mu \mathrm{L}$ propidium iodide solution ( $50 \mu \mathrm{g} / \mathrm{mL}$ solution) was then added and the cells were incubated for $1 \mathrm{~h}$ in the dark prior to flow cytometric analysis.

\section{7-Aminoactinomycin D Cell Death Assay}

Cells were harvested into $15 \mathrm{~mL}$ falcon tubes and washed twice with PBS. The cell pellet was resuspended in $400 \mu \mathrm{L}$ PBS and treated with $20 \mu \mathrm{L}(1 \mu \mathrm{g})$ of 7 -aminoactinomycin D solution. As the positive control, $0.2 \%$ Triton X-100 was added to the cell solution. Flow cytometric analysis was performed following a $10 \mathrm{~min}$ incubation.

\section{In Vitro BrdU Labeling and Immunostaining}

Cells were plated on PDL/laminin-coated glass coverslips in 24 well plates at 10,000 cells $/ \mathrm{cm}^{2}$ and incubated in proliferation medium for $48 \mathrm{~h}$. The medium was replaced with fresh proliferation medium containing test compounds or vehicle (DMSO) and incubated for another $24 \mathrm{~h}$. BrdU $(10 \mu \mathrm{M})$ was applied for $2 \mathrm{~h}$ prior to fixation. The cells were fixed with $4 \%$ PFA for $10 \mathrm{~min}$ and subsequently washed three times with PBS prior to being stained. See Supplemental Experimental Procedures for a detailed staining procedure.

\section{Fluorescence and DAB Immunostaining on Brain Tissue}

Mice were deeply anesthetized by intraperitoneal injection of xylazine and ketamine and subsequently perfused with $0.9 \% \mathrm{NaCl}$ and $4 \%$ PFA. The brains were collected and immersed in 4\% PFA solution for $24 \mathrm{~h}$, after which they equilibrated in 30\% sucrose. Serial coronal cryosections $(40 \mu \mathrm{m})$ were cut using a microtome (Leica) and stored in cryoprotection solution at $-20^{\circ} \mathrm{C}$. Every sixth section of each brain was pooled in one series and stained using standard protocols. See Supplemental Experimental Procedures for a detailed procedure and Table S7 for a list of antibodies used.

\section{Resazurin Survival Assay}

Cells were incubated in $0.05 \mathrm{mM}$ resazurin dye (7-hydroxy-3Hphenoxazin-3-one 10-oxide) for $2 \mathrm{~h}$ at $37^{\circ} \mathrm{C}$ and the fluorescence intensity was then measured in a plate reader at $560 \mathrm{~nm} \mathrm{ex/}$ $590 \mathrm{~nm}$ em filter settings.

\section{Western Blot}

Cells were collected in lysis buffer with protease inhibitor cocktail and disrupted by trituration using a syringe fitted with a $20 \mathrm{G}$ needle. The proteins were separated by SDS-PAGE and transferred to nitrocellulose membranes. The membranes were blocked and then probed with primary antibodies and horseradish peroxidase-labeled secondary antibodies. Protein bands were detected using a horseradish peroxidase/chemiluminescence system (ECL Western Blotting Substrate, Pierce) and visualized on Hyperfilm ECL (Amersham). The films were scanned and band intensities were determined using Image (http:// imagej.nih.gov/ij/).

\section{RNA Microarray}

The total RNA from monolayers treated with quercetin was prepared using the Qiagen RNeasy mini kit. The total RNA from primary cells treated with apple extract was prepared using the Qiagen RNeasy micro kit, followed by an amplification step using Ovation Pico and PicoSL WTA System V2 and Encore biotin module. RNA samples were amplified using the TotalPrep RNA amplification kit (Illumina) and hybridized to MouseWG-6 v.2.0 Expression BeadChips (Illumina). Raw data were preprocessed with quantile normalization in R/Bioconductor using the package beadarray. The array was reannotated by querying each probe sequence against the $\mathrm{mm} 9$ mouse genome using the BLAT algorithm (kindly supplied by Dr. Jim Kent; http:// hgwdev.cse.ucsc.edu/ kent/exe/linux). The genomic position of probes returning a single hit was then used to assign the probe to an NCBI Entrez Gene ID. Probes targeting the same gene ID were collapsed as a means to yield data for 21,155 unique genes. Using the Benjamini-Hochberg method, the gene expression result was corrected with adjusted $\mathrm{p}<0.05$ as the significance cutoff and then visualized using a volcano plot. The gene expression was presented as "expression relative to control," which was the result of $\log 2$ fold change. The value 1 indicates a 2 -fold change of differentially upregulated expression and -1 indicates a 2 -fold change of differentially downregulated expression. The list of differentially expressed genes was enriched into KEGG pathways (Kanehisa and Goto, 2000) and WikiPathways (Kelder et al., 2009) using WebGestalt, a web-based gene enrichment analysis tool.

\section{Real Time PCR}

Adherent cultures were washed with PBS and harvested in RLT buffer. Total RNA was prepared using the Qiagen RNeasy mini kit. The cDNA was prepared from $1 \mu \mathrm{g}$ of RNA using Superscript II kit and oligo(dT) primers. qPCR analysis was performed using SYBR Green PCR Mix (Qiagen). Thermal cycling and fluorescence analysis were performed using the $\Delta \Delta \mathrm{Ct}$ method after normalizing to the $\beta$-actin gene. See Table $S 8$ for a list of primer sequences. 


\section{Apple Extraction}

The extract was prepared from the Pinova apple cultivar, which was obtained from a local apple orchard (Obstgut Dreßler Sobrigau, Kreischa) (Schlage Obsthof) in autumn 2011. The apple peel (100 g fresh weight) and flesh (200 g fresh weight) were separately blended in $200 \mathrm{~mL} 80 \% \mathrm{MeOH}$ and then filtered through Whatman filter paper grade 1 . The process was repeated three times. The solution was then centrifuged for $10 \mathrm{~min}, 6,000 \mathrm{~g}$ at $4^{\circ} \mathrm{C}$. The supernatant was collected and dried in a rotary evaporator at $40^{\circ} \mathrm{C}$ prior to being fractionated (see Supplemental Experimental Procedures for details on the fractionation process and total flavonoid assay).

\section{Morris Water Maze}

Three weeks after apple juice supplementation, mice were trained to locate a submerged escape platform in a circular pool ( $2 \mathrm{~m}$ diameter). The water was made opaque with non-toxic titanium dioxide and kept at a temperature of $19^{\circ} \mathrm{C}$ to $20^{\circ} \mathrm{C}$. Each mouse underwent six trials a day for 5 consecutive days. On day 4 the position of the platform was changed to the opposite quadrant (reversal). The starting position was changed every day and remained constant for all trials each day. Mice were allowed to search for the platform for up to $120 \mathrm{~s}$. At the end of each trial, they were guided to the platform and allowed to remain there for $15 \mathrm{~s}$. The first $30 \mathrm{~s}$ on the first trial of day 4 was used as the probe trial. Swim paths were recorded using Ethovision (Noldus) and further analyzed using MatLab (MathWorks, USA).

\section{In Vivo 3,5-DHBA Treatment}

3,5-DHBA was prepared fresh every day and dissolved in 5\% ethanol in $0.9 \% \mathrm{NaCl}$ to administer at doses of $15.625,31.25$, $62.5,125$, and $250 \mathrm{mg} / \mathrm{kg}$ body weight to female Balb/c mice. 3,5-DHBA was administered once daily for 14 days via intraperitoneal injection. One hour prior to the first 3,5-DHBA administration, mice received two BrdU injections $(50 \mathrm{mg} / \mathrm{kg}$ ), separated by $1 \mathrm{~h}$.

\section{Statistical Analysis}

Statistical analysis was performed using GraphPad Prism software (v.5.0, GraphPad Software). Microarray data analysis was performed using $\mathrm{R}$ for Mac OS X (3.1.1). The false discovery rate method was applied to perform multiple comparison tests on the microarray data. All data are shown as means with SEM. In figures the significance levels are denoted as ${ }^{*} \mathrm{p}<0.05,{ }^{* *} \mathrm{p}<0.01,{ }^{* * *} \mathrm{p}<$ 0.001 , and ${ }^{* * * *} \mathrm{p}<0.0001$.

\section{Data and Code Availability}

The microarray expression dataset used for analysis, as well as the raw data files, has been deposited in the GEO repository (http:// www.ncbi.nlm.nih.gov/geo/) under accession GSE150803.

\section{SUPPLEMENTAL INFORMATION}

Supplemental information can be found online at https://doi.org/ 10.1016/j.stemcr.2021.01.005.

\section{AUTHOR CONTRIBUTIONS}

Conceptualization, M.I., G.B.R.-R., and G.K.; investigation, M.I., T.L.W., Z.N., J.L-M., C.B., V.S.A., M.B., E.A.L., L.O.L, and A.M.S.; formal analysis, R.W.O.; writing - original draft, M.I., T.L.W., and G.K.; writing - review \& editing, M.I., T.L.W., G.K., G.B.R.-R, and R.W.O.; funding acquisition, M.I., G.K., N.H., G.B.R.-R, and T.L.W.; supervision, T.L.W., G.K., and G.B.R.-R.

\section{ACKNOWLEDGMENTS}

This project was funded by the Deutsche Akademischer Austauschdienst, Deutsche Forschungsgemeinschaft Sonderforschungsbereich 655, Bundesministerium für Bildung und Forschung, Consejo Nacional de Ciencia y Tecnología (CONACYT, México; grant 147377), NIPRFM (SIC 2000), and the Brazil Family Foundation for Neurology.

Received: July 20, 2020

Revised: January 10, 2021

Accepted: January 12, 2021

Published: February 11, 2021

\section{REFERENCES}

Angamo, E.A., Rosner, J., Liotta, A., Kovacs, R., and Heinemann, U. (2016). A neuronal lactate uptake inhibitor slows recovery of extracellular ion concentration changes in the hippocampal CA3 region by affecting energy metabolism. J. Neurophysiol. $116,2420-2430$.

Aprea, J., Prenninger, S., Dori, M., Ghosh, T., Monasor, L.S., Wessendorf, E., Zocher, S., Massalini, S., Alexopoulou, D., Lesche, M., et al. (2013). Transcriptome sequencing during mouse brain development identifies long non-coding RNAs functionally involved in neurogenic commitment. EMBO J. 32, 3145-3160.

Babu, H., Cheung, G., Kettenmann, H., Palmer, T.D., and Kempermann, G. (2007). Enriched monolayer precursor cell cultures from micro-dissected adult mouse dentate gyrus yield functional granule cell-like neurons. PLoS One 2, e388.

Bell, K.F., Al-Mubarak, B., Martel, M.A., McKay, S., Wheelan, N., Hasel, P., Markus, N.M., Baxter, P., Deighton, R.F., Serio, A., et al. (2015). Neuronal development is promoted by weakened intrinsic antioxidant defences due to epigenetic repression of Nrf2. Nat. Commun. 6, 7066.

Bhagwat, S., Haytowitz, D.B. (2016). USDA Database for the Flavonoid Content of Selected Foods. Release 3.2 (November 2015). Nutrient Data Laboratory, Beltsville Human Nutrition Research Center, ARS, USDA.

Bondonno, C.P., Downey, L.A., Croft, K.D., Scholey, A., Stough, C., Yang, X., Considine, M.J., Ward, N.C., Puddey, I.B., Swinny, E., et al. (2014). The acute effect of flavonoid-rich apples and nitrate-rich spinach on cognitive performance and mood in healthy men and women. Food Funct. 5, 849-858.

Cai, T.Q., Ren, N., Jin, L., Cheng, K., Kash, S., Chen, R., Wright, S.D., Taggart, A.K., and Waters, M.G. (2008). Role of GPR81 in lactate-mediated reduction of adipose lipolysis. Biochem. Biophys. Res. Commun. 377, 987-991. 
Castillo, X., Rosafio, K., Wyss, M.T., Drandarov, K., Buck, A., Pellerin, L., Weber, B., and Hirt, L. (2015). A probable dual mode of action for both L- and D-lactate neuroprotection in cerebral ischemia. J. Cereb. Blood Flow Metab. 35, 1561-1569.

Dillard, C.J., and German, J.B. (2000). Phytochemicals: nutraceuticals and human health. J. Sci. Food Agric. 80, 1744-1756.

Garthe, A., Behr, J., and Kempermann, G. (2009). Adult-generated hippocampal neurons allow the flexible use of spatially precise learning strategies. PLoS One 4, e5464.

Georgiev, V., Ananga, A., and Tsolova, V. (2014). Recent advances and uses of grape flavonoids as nutraceuticals. Nutrients 6, 391-415.

Guo, H., Wang, R., Wang, D., Wang, S., Zhou, J., Chai, Z., Yao, S., Li, J., Lu, L., Liu, Y., et al. (2020). Deliver anti-PD-L1 into brain by p-hydroxybenzoic acid to enhance immunotherapeutic effect for glioblastoma. J. Control Release 320, 63-72.

Hubkova, B., Velika, B., Birkova, A., Guzy, J., and Marekova, M. (2014). Hydroxybenzoic acids and their derivatives as peroxynitrite scavengers. Free Radic. Biol. Med. 75, S33-S34.

Ishisaka, A., Ichikawa, S., Sakakibara, H., Piskula, M.K., Nakamura, T., Kato, Y., Ito, M., Miyamoto, K., Tsuji, A., Kawai, Y., et al. (2011). Accumulation of orally administered quercetin in brain tissue and its antioxidative effects in rats. Free Radic. Biol. Med. 51, 13291336.

Itoh, K., Chiba, T., Takahashi, S., Ishii, T., Igarashi, K., Katoh, Y., Oyake, T., Hayashi, N., Satoh, K., Hatayama, I., et al. (1997). An Nrf2/small Maf heterodimer mediates the induction of phase II detoxifying enzyme genes through antioxidant response elements. Biochem. Biophys. Res. Commun. 236, 313-322.

Kanehisa, M., and Goto, S. (2000). KEGG: Kyoto encyclopedia of genes and genomes. Nucleic Acids Res. 28, 27-30. https://doi. org/10.1093/nar/28.1.27.

Kelder, T., Pico, A.R., Hanspers, K., van Iersel, M.P., Evelo, C., and Conklin, B.R. (2009). Mining biological pathways using WikiPathways web services. PLoS One 4, e6447. https://doi.org/10.1371/ journal.pone.0006447.

Lev-Vachnish, Y., Cadury, S., Rotter-Maskowitz, A., Feldman, N., Roichman, A., Illouz, T., Varvak, A., Nicola, R., Madar, R., and Okun, E. (2019). L-Lactate promotes adult hippocampal neurogenesis. Front Neurosci. 13, 403.

Liu, C., Kuei, C., Zhu, J., Yu, J., Zhang, L., Shih, A., Mirzadegan, T., Shelton, J., Sutton, S., Connelly, M.A., et al. (2012). 3,5-Dihydroxybenzoic acid, a specific agonist for hydroxycarboxylic acid 1, inhibits lipolysis in adipocytes. J. Pharmacol. Exp. Ther. 341, 794-801.

Moon, J.S., Kim, S.H., Oh, S.H., Jeong, Y.W., Kang, J.H., Park, J.C., Son, H.J., Bae, S., Park, B.I., Kim, M.S., et al. (2014). Relaxin augments BMP-2-induced osteoblast differentiation and bone formation. J. Bone Miner Res. 29, 1586-1596.

Nguyen, T., Nioi, P., and Pickett, C.B. (2009). The Nrf2-antioxidant response element signaling pathway and its activation by oxidative stress. J. Biol. Chem. 284, 13291-13295.

Nguyen, T., Sherratt, P.J., Nioi, P., Yang, C.S., and Pickett, C.B. (2005). Nrf2 controls constitutive and inducible expression of ARE-driven genes through a dynamic pathway involving nucleocytoplasmic shuttling by Keap1. J. Biol. Chem. 280, 32485-32492.
Nguyen, T., Sherratt, P.J., and Pickett, C.B. (2003). Regulatory mechanisms controlling gene expression mediated by the antioxidant response element. Annu. Rev. Pharmacol. Toxicol. $43,233-260$.

Nichols, M., Zhang, J., Polster, B.M., Elustondo, P.A., Thirumaran, A., Pavlov, E.V., and Robertson, G.S. (2015). Synergistic neuroprotection by epicatechin and quercetin: activation of convergent mitochondrial signaling pathways. Neuroscience 308, 75-94.

Ohno, Y., Oyama, A., Kaneko, H., Egawa, T., Yokoyama, S., Sugiura, T., Ohira, Y., Yoshioka, T., and Goto, K. (2018). Lactate increases myotube diameter via activation of MEK/ERK pathway in C2C12 cells. Acta Physiol. 223, e13042.

Ortiz-Lopez, L., Marquez-Valadez, B., Gomez-Sanchez, A., Silva-Lucero, M.D., Torres-Perez, M., Tellez-Ballesteros, R.I., Ichwan, M., Meraz-Rios, M.A., Kempermann, G., and Ramirez-Rodriguez, G.B. (2016). Green tea compound epigallo-catechin-3-gallate (EGCG) increases neuronal survival in adult hippocampal neurogenesis in vivo and in vitro. Neuroscience 322, 208-220.

Pinto, M., Benfeito, S., Fernandes, C., and Borges, F. (2020). Antioxidant therapy, oxidative stress, and blood-brain barrier: the road of dietary antioxidants. In Oxidative Stress and Dietary Antioxidants in Neurological Diseases, V.R.P. Colin and R. Martin, eds. (Academic Press), pp. 125-141.

Plumpe, T., Ehninger, D., Steiner, B., Klempin, F., Jessberger, S., Brandt, M., Romer, B., Rodriguez, G.R., Kronenberg, G., and Kempermann, G. (2006). Variability of doublecortin-associated dendrite maturation in adult hippocampal neurogenesis is independent of the regulation of precursor cell proliferation. BMC Neurosci. 7,77 .

Prozorovski, T., Schulze-Topphoff, U., Glumm, R., Baumgart, J., Schroter, F., Ninnemann, O., Siegert, E., Bendix, I., Brustle, O., Nitsch, R., et al. (2008). Sirt1 contributes critically to the redoxdependent fate of neural progenitors. Nat. Cell Biol. 10, 385-394.

Remington, R., Chan, A., Lepore, A., Kotlya, E., and Shea, T.B. (2010). Apple juice improved behavioral but not cognitive symptoms in moderate-to-late stage Alzheimer's disease in an open-label pilot study. Am. J. Alzheimers Dis. Other Demen. 25, 367-371.

Soni, M.G., Carabin, I.G., and Burdock, G.A. (2005). Safety assessment of esters of p-hydroxybenzoic acid (parabens). Food Chem. Toxicol. 43, 985-1015.

Spencer, J.P.E. (2009). The impact of flavonoids on memory: physiological and molecular considerations. Chem. Soc. Rev. 38, 1152-1161.

Tchantchou, F., Chan, A., Kifle, L., Ortiz, D., and Shea, T.B. (2005). Apple juice concentrate prevents oxidative damage and impaired maze performance in aged mice. J. Alzheimers Dis. 8, 283-287.

Torres-Perez, M., Tellez-Ballesteros, R.I., Ortiz-Lopez, L., Ichwan, M., Vega-Rivera, N.M., Castro-Garcia, M., Gomez-Sanchez, A., Kempermann, G., and Ramirez-Rodriguez, G.B. (2015). Resveratrol enhances neuroplastic changes, including hippocampal neurogenesis, and memory in Balb/C Mice at six months of age. PLoS One 10, e0145687.

van der Made, S.M., Plat, J., and Mensink, R.P. (2015). Resveratrol does not influence metabolic risk markers related to cardiovascular 
health in overweight and slightly obese subjects: a randomized, placebo-controlled crossover trial. PLoS One 10, e0118393.

Viggiano, A., Viggiano, A., Monda, M., Turco, I., Incarnato, L., Vinno, V., Viggiano, E., Baccari, M.E., and De Luca, B. (2006). Annurca apple-rich diet restores long-term potentiation and induces behavioral modifications in aged rats. Exp. Neurol. 199, 354-361.

Walker, T.L., and Kempermann, G. (2014). One mouse, two cultures: isolation and culture of adult neural stem cells from the two neurogenic zones of individual mice. J. Vis. Exp. 25, e51225.
Wang, J., Cui, Y., Yu, Z., Wang, W., Cheng, X., Ji, W., Guo, S., Zhou, Q., Wu, N., Chen, Y., et al. (2019). Brain endothelial cells maintain lactate homeostasis and control adult hippocampal neurogenesis. Cell Stem Cell 25, 754-767.

Yoo, K.Y., Choi, J.H., Hwang, I.K., Lee, C.H., Lee, S.O., Han, S.M., Shin, H.C., Kang, I.J., and Won, M.H. (2010). (-)-Epigallocatechin-3-gallate increases cell proliferation and neuroblasts in the subgranular zone of the dentate gyrus in adult mice. Phytother. Res. 24, 1065-1070. 